\title{
Christliche Transformation des antiken Dialogs bei Justin und Minucius Felix
}

\author{
von Katharina Heyden
}

\begin{abstract}
Apologetische Dialoge aus der Feder früher Christen stehen weder bei Theologen noch bei Philologen in hohem Ansehen. Dies zeigt sich schon darin, dass seit fast vierzig Jahren keine zusammenhängende Darstellung des christlichen Dialogs unternommen wurde ${ }^{1}$ - was umso erstaunlicher ist, als das Thema Religionsdialog in dieser Zeit an gesellschaftlicher Aktualität gewonnen hat. Die Vermutung drängt sich auf, dass gerade in der Aktualität des Themas das Problem liegt. Heutige Leser antiker Dialoge sind bewusst oder unbewusst von postmodernen Diskurstheorien geprägt ${ }^{2}$. Diese implizieren ein Verständnis von Dialog, das den apologetischen Dialog von vornherein als Ding der Unmöglichkeit erscheinen lässt: Steht nicht, so mag man fragen, die Eigendynamik des Dialogischen dem Zweck eines
\end{abstract}

1 Bereits 1688 hatte M. Müller in Wittenberg in einer knappen Dissertatio historica de dialogis doctorum veteris ecclesiae den Versuch unternommen, alle christlichen Dialoge zu sammeln und zum antiken philosophischen Dialog in Beziehung zu setzen. Erst O. Zöckler widmete sich dem Thema im Jahr 1893 wieder in einem kurzen Aufsatz: O. Zöckler, Der Dialog im Dienste der Apologetik, BGI N.F. 14, 1893, 209-230. Nachdem Rudolf Hirzel in seinem Standardwerk zur Literaturgeschichte des Dialogs (R. Hirzel, Der Dialog. Ein literarhistorischer Versuch, 2 Bde., Leipzig 1895 [ND Hildesheim 1963]) nur am Rande auf die frühchristliche Literatur eingegangen war (Bd. 2, 366-380), legten Martin Hoffmann und Bernd Reiner Voss fast zeitgleich Monographien zum antiken christlichen Dialog vor (M. Hoffmann, Der Dialog bei den christlichen Schriftstellern der ersten vier Jahrhunderte, TU 96, Berlin 1966; B.R. Voss, Der Dialog in der frühchristlichen Literatur, STA 9, München 1970). Für eine kritische Auseinandersetzung mit diesen Entwürfen vgl. P.L. Schmidt, Zur Typologie und Literarisierung des frühchristlichen lateinischen Dialogs, in: M. Fuhrmann (Hg.), Christianisme et formes littéraires de l'antiquité tardive en occident. Entretiens sur l'antiquité classique 23, Genf 1977, 101-190. Den byzantinischen antijüdischen Dialogen hat A. Külzer seine Habilitationsschrift gewidmet: A. Külzer, Disputationes graecae contra Iudaeos. Untersuchungen zur byzantinischen antijüdischen Dialogliteratur und ihrem Judenbild, ByA 18, Leipzig/Stuttgart 1999. Für den philosophischen Dialog liegt seit kurzem eine weitere Monographie vor, die allerdings ausdrücklich nicht den Anspruch erhebt, das Werk Hirzels zu ersetzen: V. Hösle, Der philosophische Dialog. Eine Poetik und Hermeneutik, München 2006.

2 Die (post)modernen Diskurstheorien können hier nicht erschöpfend referiert werden. Verwiesen sei nur auf die normative Beschreibung eines „echten“ Gesprächs bei H.-G. Gadamer, Wahrheit und Methode. Grundzüge einer philosophischen Hermeneutik, Tübingen ${ }^{6} 1996$, besonders 387, und die daran anknüpfende pneumatologische Deutung von W. Pannenberg, Sprechakt und Gespräch, in: K. Stierle/R. Warning, Das Gespräch. Politik und Hermeneutik, München ${ }^{2}$ 1996, 65-76. Der Sammelband von Stierle/Warning ist insgesamt instruktiv. 
apologetischen Werkes prinzipiell entgegen, da der Dialog strukturell von Offenheit geprägt ist, während die Apologie grundsätzlich die Wahrheit des eigenen Glaubens voraussetzt und allein die Vermittlung dieser unhinterfragten Wahrheit zum Ziel hat? Muss man daher nicht von Missbrauch oder Dekadenz des Dialogs sprechen, wenn er in den Dienst der christlichen Apologie gestellt wird?

Die beiden Forscher, die sich zuletzt umfassend mit antiker christlicher Dialogliteratur befassten, haben genau dieses Urteil gefällt. Martin Hoffmann bezeichnete den christlichen literarischen Dialog als „Erstarrung“, „Sklerose“, „völlige Entstellung“ der ursprünglichen - und das heißt: platonischen, also dialektisch-maieutischen - Dialogform ${ }^{3}$, Bernd Reiner Voss brandmarkte ihn als „wirklichkeitsnahe Gebrauchsliteratur, die künstlerischen Rang nicht in Anspruch nehmen“, ja „in der Regel nicht als Literatur angesehen werden“ könne, weil sie „rein praktischen Zwecken" diene ${ }^{4}$. Im Hintergrund solcher Urteile steht - bewusst oder unbewusst - das oben skizzierte moderne Ideal eines Dialogs, das unsachgemäß auf die antiken Texte übertragen wird ${ }^{5}$. Dies weist darauf hin, dass bisher noch keine Hermeneutik für christliche Dialogliteratur - geschweige denn für christliche apologetische Dialoge - entwickelt wurde, die einen angemessenen Zugriff auf die Texte ermöglichte ${ }^{6}$.

Die folgenden Ausführungen können diese Lücke nicht erschöpfend füllen. Anhand der Kategorie der „Inszenierung“ soll aber zumindest angedeutet werden, in welcher Weise eine Hermeneutik christlicher Dialog-

3 Zitate aus Hoffmann, Dialog (wie Anm. 1), 162. „Das heterogene inhaltliche Element nämlich die in der Offenbarung vorgegebene Wahrheit - bricht die Form um: aus der Wahrheitssuche wird die Offenbarungskatechese. Die Dialogform ist nun nicht mehr Ausdruck des Kampfes um die Wahrheit, sondern für die Vermittlung der Wahrheit“ (S. 162). Hoffmann traut den christlichen Autoren noch nicht einmal ein Problembewusstsein zu: „Dieser Umbruch kam den meisten Dialogschriftstellern nicht zum Bewusstsein; man will einen philosophischen Dialog der literarischen Tradition schreiben, der christliche Inhalt modifiziert aber die Form bis zur völligen Entstellung" (S. 162).

4 Voss, Dialog (wie Anm. 1), 328.363.

5 Dies wird etwa an folgender Äußerung von Hoffmann, Dialog (wie Anm. 1), 162 deutlich: „Das Maß der dialogischen Sklerose ist bei den einzelnen Autoren verschieden. [...] Der Offenbarungscharakter der kirchlichen Lehre, die autoritativ als vorgegebene christliche Wahrheit vertreten wird, macht in jedem Fall ein echtes Gespräch mit dem Gegenüber unmöglich.“

6 Schmidt, Typologie (wie Anm. 1) machte zwar in seiner kritischen Reaktion auf Hoffmann, Dialog (wie Anm. 1) und Voss, Dialog (wie Anm. 1) auf die Grenzen und Probleme des ausschließlich literaturwissenschaftlichen Ansatzes aufmerksam und entwickelte eine Typologie des christlichen Dialogs. Er dringt jedoch nur ganz am Rande zu einem positiven Gegenentwurf und zu Fragen der Hermeneutik vor. Külzer, Disputationes graecae (wie Anm. 1), 91f. betont den „Vorbereitungscharakter“ der christlichen apologetischen Dialoge, ihre „Intention, auf wirkliche Debatten hinzuführen“. Dies mag für die byzantinischen antijüdischen Dialoge, mit denen sich Külzer befasst, zutreffen. Für antike und spätantike Texte erweist sich dieser Ansatz jedoch als unzureichend, weil sie - wie zu zeigen sein wird - zugleich auch einen literarischen Anspruch haben. Hösle, Der philosophische Dialog (wie Anm. 1), 30-56 bringt instruktive Gedanken zur Hermeneutik philosophischer Dialoge, geht aber nur ganz am Rande auf christliche Dialoge ein. 
literatur zu entwickeln wäre (1). Vor diesem Hintergrund werden exemplarische Beobachtungen zur Inszenierung der beiden ältesten erhaltenen christlichen Religionsdialoge - Justins Dialog mit dem Juden Tryphon und der Octavius des Minucius Felix - vorgestellt (2-3), die abschließend als christliche Transformationen des antiken philosophischen Dialogs gewürdigt werden (4).

\section{Zur Interpretation literarischer Dialoge}

\section{Begriffliche Differenzierung}

Um vorschnelle und historisch unangemessene Urteile über antike literarische Dialoge zu vermeiden, müssen bei der Verwendung des Begriffs „Dialog“ zunächst drei Bedeutungsebenen unterschieden werden, die im heutigen alltäglichen Sprachgebrauch recht unreflektiert vermischt erscheinen: Mit „Dialog“ kann zum einen das mündliche Gespräch, zum anderen die literarische Gattung, schließlich das abstrakte Prinzip des Dialogischen bezeichnet werden. Diese Bedeutungen stehen zwar nicht unvermittelt nebeneinander, da der literarische Dialog als Mimesis mündlicher Rede in einem gewissen Grad auch das dialogische Prinzip in Anspruch nimmt. Dennoch kann der literarische Dialog nicht mit Deutungskategorien aus der mündlichen Kommunikation interpretiert oder gar an ihnen gemessen werden. Wenn etwa Bernd Reiner Voss an den christlichen Dialogen der Spätantike kritisierte, dass nicht „Wahrheitsfindung“, sondern „Wahrheitsvermittlung “ ihr Ziel sei”, so beruht diese Kritik auf einer unangemessenen Prämisse: dass nämlich ein Dialog grundsätzlich ergebnisoffen und darauf angelegt sein müsse, „eine allen Partnern unbekannte Erkenntnis zu gewinnen "8. Mag diese Zielsetzung für das mündliche Gespräch bis zu einem gewissen Grad zutreffen - sie entspricht jedenfalls den Ansprüchen moderner Diskurstheorien -, so erweist sie sich mit Blick auf literarische Dialoge, zumal solche der Antike, als falsch. Selbst bei Platon, der doch allenthalben als der unübertroffene Verfasser literarischer Dialoge und als Richtschnur aller Späteren angeführt wird ${ }^{9}$, wäre zu fragen, inwiefern von Ergebnisoffenheit des Dialogs gesprochen werden kann. Auch hier ist das literarisch inszenierte Gespräch eine Methode gerade der Erkenntnisvermittlung. Vermittelt werden soll freilich nicht allein ein bestimmter Inhalt, sondern vor allem eine Methode, ein Weg zur Erkenntnis ${ }^{10}$. Entsprechend

\footnotetext{
Voss, Dialog (wie Anm. 1), 359.

Voss, Dialog (wie Anm. 1), 359.

Die Orientierung an Platon prägt alle in Anm. 1 genannten Werke mehr oder weniger explizit. Hösle, Der philosophische Dialog (wie Anm. 1) orientiert sich ganz ausdrücklich an Platon als dem „Gründer und vollkommensten Meister dieses Genres“ (S. 10).

10 Vgl. W. Wieland, Platon und die Formen des Wissens, Göttingen ${ }^{2} 1999$. Auf die Interaktion von „Dialogform und Argument“ bei Platon hat Norbert Blößner am Beispiel der
} 
vielfältig sind daher auch die Dialogformen: Diogenes Laertios etwa unterscheidet im 3. Jahrhundert n.Chr. in seiner diäretischen Typologie der platonischen Dialoge insgesamt 14 Dialogtypen und hält den maieutischen keineswegs für den „eigentlichen“ Dialog. Daneben nennt er mit dem

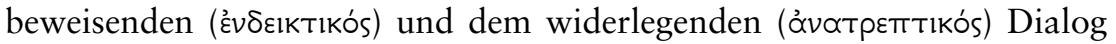

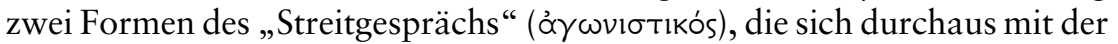
Idee eines apologetischen Dialogs vereinbaren lassen ${ }^{11}$. An diesen spätantiken Vorbildern, nicht an modernen Idealen, sollten auch die christlichen Autoren gemessen werden.

\section{Der literarische Dialog als Inszenierung}

Der literarische Dialog hat als Textgattung eigene Strukturelemente, die von der weiteren Bedeutung des Wortfeldes zwar nicht getrennt, aber unterschieden werden müssen, wenn die spezifische Funktion der Texte zur Geltung kommen soll ${ }^{12}$. Anders als das mündliche Gespräch ist der literarische Dia$\log$ „schriftliche Inszenierung mündlicher Kommunikation“13 und damit dem Gestaltungswillen eines Autors unterworfen. Wer sich aus literarischen Dialogen unmittelbaren Aufschluss über tatsächliche Religionsdispute erhofft, wird daher in den allermeisten Fällen enttäuscht. Die Dialoge mögen zwar in vielen Fällen vor dem Hintergrund realer Dispute verfasst worden sein, sie geben jedoch nur selten den tatsächlichen Verlauf eines solchen Gesprächs wieder, so dass der berechtigte Eindruck entstehen kann, dass „Fragen nach der Historizität sinnlos werden“"14. Man wird den Texten aber auch nicht gerecht, wenn man sie daran misst, in welchem Maß das

Politeia nachdrücklich hingewiesen (N. Blößner, Dialogform und Argument. Studien zu Platons ,Politeia“, AAWLM.G 1997/1, Stuttgart 1997, besonders 242-288).

11 D.L., Vitae philosophorum III 49 (BSGRT, 222,21-223,7 Marcovich). Diogenes unterschei-

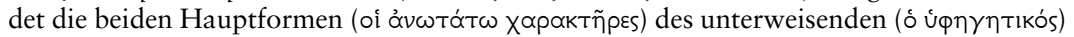

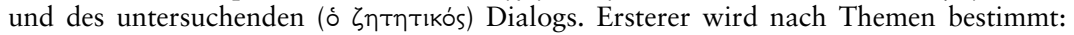

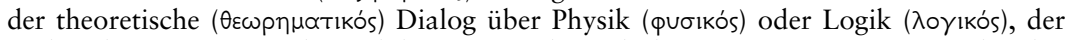

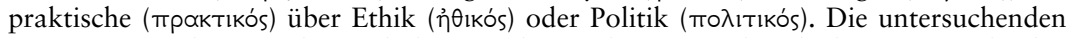

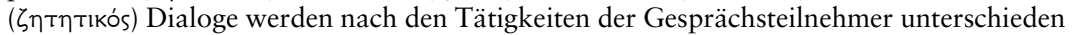

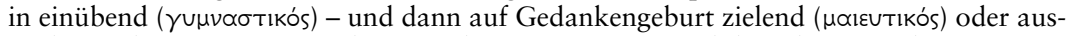

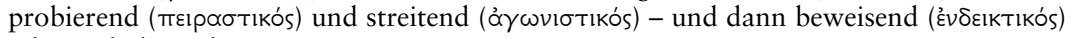

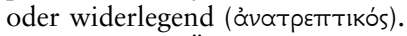

12 Die folgenden Überlegungen sind von Arbeiten inspiriert, die in den letzten Jahren im Rahmen des von Prof. Klaus W. Hempfer geleiteten Forschungsprojekts „Performativität und episteme: Die Dialogisierung des theoretischen Diskurses in der Renaissance" an der FU Berlin zur Dialogtheorie entstanden sind: K.W. Hempfer (Hg.), Möglichkeiten des Dialogs. Struktur und Funktion einer literarischen Gattung zwischen Mittelalter und Renaissance in Italien, Text und Kontext 15, Stuttgart 2002; ders. (Hg.), Poetik des Dialogs. Aktuelle Theorie und rinascimentales Selbstverständnis, Text und Kontext 21, Stuttgart 2004.

13 K.W. Hempfer, Lektüren von Dialogen, in: ders. (Hg.), Möglichkeiten des Dialogs (wie Anm. 12), 1-38; vgl. H. Honnacker, Der literarische Dialog des Primo Cinquecento. Inszenierungsstrategien und ,Spielraum', SaeSp 40, Baden-Baden 2002, 19-22.

14 Hoffmann, Dialog (wie Anm. 1), 161. 
Ideal dialogischer Freiheit in ihnen verwirklicht ist. Es kommt vielmehr darauf an, die literarischen Inszenierungsstrategien aufzudecken, derer sich der Autor zum Zweck der Erkenntnisvermittlung bedient.

Besonders wichtig, weil für die Gattung des Dialogs spezifisch ist die Überlagerung verschiedener Ebenen der Inszenierung, die bei der Interpretation sorgsam unterschieden und in ihrem Zusammenspiel gedeutet werden müssen:

(1) Auf der Darstellungsebene (narrative Einkleidung, histoire) konstituiert der Autor die Welt, den Argumentationszusammenhang, in den sich das Gespräch einzeichnet: der Leser wird in eine fiktive Szenerie versetzt. Durch die Situierung des Diskurses an einem bestimmten Ort zu einer bestimmten Zeit, durch die Charakterisierung der Personen und die Darstellung von Nebenhandlungen wird die Phantasie des Lesers und damit eine emotionale Ebene der Rezeption in einer Weise angesprochen, wie sie etwa dem Traktat völlig fremd ist. Der Grad der Fiktion kann dabei prinzipiell sehr unterschiedlich ausgeprägt sein.

(2) Die Argumentationsebene (Gesprächsteile, discours) nimmt naturgemäß den größten Raum eines literarischen Dialogs ein. In die fiktiv inszenierte Situation werden Fragen und Probleme eingezeichnet, die der tatsächlichen Welt der Leser des Dialogs entnommen sind - im Fall christlich-apologetischer Dialoge die Frage nach Legitimität und Wahrheit des christlichen Glaubens angesichts konkurrierender Wahrheitsansprüche. Die Argumentation lebt von der Nachahmung mündlicher dialogischer Rede: Gedankengänge bauen nicht notwendig schlüssig aufeinander auf, sondern speisen sich aus dem lebendigen, aber gerade deshalb nicht immer stringenten Wechselspiel von Rede und Gegenrede. Die Argumente können mehrfach in Frage gestellt, gebrochen, verworfen werden, sie können sich im Laufe des Gesprächs als nicht tragfähig und revisionsbedürftig erweisen. Während der Leser eines Traktats geprüfte, geschliffene und insofern „fertige " und klar nachvollziehbare Gedanken präsentiert bekommt, nimmt er bei der Lektüre eines Dialogs an der Entstehung von Argumenten teil. Auch hier ist zu beachten, dass Gesprächsgänge bewusst inszeniert werden ${ }^{15}$.

So kann der Autor etwa durch bestimmte sprachliche Eigenheiten der Personen, durch die Gewichtung von Redeanteilen, durch verschiedene Grade von Monologizität und Dialogizität und nicht zuletzt durch die Interaktion mit der Darstellungsebene eine implizite Kommentierung der scheinbar nur protokollarisch wiedergegebenen Argumente vornehmen.

(3) Die paratextuelle Ebene (Titel, Proömium, Schlussnotiz) gibt häufig Aufschluss über den Autor, die Adressaten und den intendierten Gebrauch des Textes. Allerdings muss auch hier noch mit Inszenierung, genauer: mit Selbstinszenierung des Autors gerechnet werden, die im Blick auf die Autorenintention aufschlussreich sein kann.

15 Hempfer, Lektüren (wie Anm. 13), 22 spricht in diesem Zusammenhang von einem „Argumentations-Spiel“. 
Aus der Überlagerung dieser Ebenen resultiert eine spezifische Komplexität des literarischen Dialogs, die bei der Interpretation zu berücksichtigen is $\mathrm{t}^{16}$. Der Interpret wird dieser Komplexität nicht gerecht, wenn er die Position des Autors vollständig in einer der dargestellten Personen verwirklicht sieht. Es ist zwar möglich, aber nicht a priori vorauszusetzen, dass eine Person als Sprachrohr des Autors fungiert. Nur aus dem literarischen Miteinander der verschiedenen Ebenen ist die Autorenintention zu erheben: Nicht eine Person, sondern der Dialogtext als ganzer muss als Sprachrohr des Autors interpretiert werden ${ }^{17}$.

\section{Die Pragmatik literarischer Dialoge}

Die Überlagerung von narrativer, argumentativer und paratextueller Ebene macht die spezifische Möglichkeit literarischer Dialoge aus und weist auf ihre Funktion, ihren „Sitz im Leben“ hin: Literarische Dialoge sind fiktionale Texte, die in einen realen Diskurszusammenhang eintreten ${ }^{18}$. Wie jeder Text trägt auch der Dialog den Geist seiner Zeit in sich und gibt daher Aufschluss über die tatsächlich stattfindenden Auseinandersetzungen, die Anlass und Hintergrund für die literarische Verarbeitung bilden ${ }^{19}$. Darüber hinaus aber haben Dialoge als fiktionale Texte, die in einen realen Diskurszusammenhang eintreten, auch eine operative Funktion nach au$\beta^{20}{ }^{20}$. Indem der Autor seine Argumente typologischen Personen in fiktiven Situationen in den Mund legt, ermöglicht er die Identifikation seiner Leser mit bestimmten Dialogfiguren. So bietet die literarische Inszenierung eines Gesprächs dem Autor die Möglichkeit, in einen tatsächlich stattfindenden Diskurs durch „Projektierung, Modellierung oder auch Manipulation von Diskursgemeinschaften " 21 einzugreifen und seinen Lesern modellhaft Argumente für tatsächlich stattfindende Auseinandersetzungen an die Hand zu geben. Die spezifische apologetische Funktion eines Dialogs kann daher nur durch das Ineinanderblenden von fiktionaler Inszenierung und konkreter historischer Situation erhoben werden.

16 Hempfer, Lektüren (wie Anm. 13), 19 warnt zu Recht vor einer „Monologisierung des Dialogs“, in der literarische Dialoge gegen ihre charakteristische Polyperspektivik wie Traktate oder andere Gattungen des theoretischen Diskurses behandelt werden.

17 Vgl. Häsner, Dialog (wie Anm. 12), 16.

18 Häsner, Dialog (wie Anm. 12), 18.

19 Vgl. E.W.B. Hess-Lüttich, Art. Gespräch, Historisches Wörterbuch zur Rhetorik 3, 1996, (929-947) 933: „Der literarische Autor ist auch Praktiker des Gesprächs, sein Alltagswissen über die in seiner eigenen Kommunikationserfahrung gewonnene Gesprächserfahrung läßt ihn deren grundlegende Regularitäten, deren Gefährdungen und Abweichungen, sensibel registrieren und stilistisch verfremden im Rahmen seines ästhetischen Programms. “

20 Vgl. Häsner, Dialog (wie Anm. 12): der Dialog sei „culture in action“ (S. 50), die operative Funktion sei die „exklusive Möglichkeit des Dialogs“ (S. 52), der Dialog das „eminent performative Genre“ (S. 54).

21 Häsner, Dialog (wie Anm. 12), 49. 
Die folgenden Beobachtungen zu Justin und Minucius Felix erheben nicht den Anspruch, die hier skizzierte Methodik im Sinne einer Gesamtinterpretation der Dialoge anzuwenden. Sie sollen vielmehr exemplarisch verdeutlichen, wie die Analyse der Inszenierung eines literarischen Dialogs das Verständnis des Werkes bereichern kann.

\section{Justins Dialog mit dem Juden Tryphon}

Justins Dialog mit dem Juden Tryphon, um 155 n.Chr. als Reflex eines 20 Jahre zuvor in Ephesus geführten Gesprächs in Rom verfasst ${ }^{22}$, ist der älteste erhaltene christlich-apologetische Dialog. Ob Justin tatsächlich als „Erfinder“ des christlichen Dialogs angesehen werden kann, bleibt angesichts des ebenfalls im 2. Jahrhundert entstandenen Dialogs zwischen Jason und Papiskos ${ }^{23}$ zwar fraglich. In jedem Fall aber ist Justin der erste christliche Autor, der sich nachweislich auf die klassische Dialogtradition bezieht und sie für die christliche Verkündigung adaptiert.

Insgesamt macht der Dialog mit dem Juden Tryphon zunächst einen ungeordneten, ja assoziativ-willkürlichen Eindruck. Dem modernen Leser mag er wie eine „überdimensionale Schriftensammlung“ erscheinen, die „nur notdürftig eine gewisse dialogische Verbrämung erhalten“ ${ }^{24}$ hat. Daher wurde Justin immer wieder für sein literarisches Unvermögen im allgemeinen und für die zahlreichen Wiederholungen, Abschweifungen und Exkurse im besonderen getadelt ${ }^{25}$. Allerdings hat man dabei zweierlei übersehen. Zum einen gibt Justin gleich zu Beginn seines Werkes, im so genannten „platonischen Vorgespräch“ (Dialog mit dem Juden Tryphon 1-11) eine Probe für seine literarische Kunstfertigkeit. Zum anderen nimmt Justin seinen Lesern im zweiten, sehr viel längeren Teil des Dialogs (Dialog mit dem Juden Tryphon 12-141) die Kritik am vermeintlich unstrukturierten

22 Zitate folgen der Edition von M. Marcovich: Iustini Martyris Dialogus cum Tryphone, ed. by Miroslav Marcovich, PTS 47, Berlin/New York 1997. Justin weist in dial. 120,6 (PTS 47, 278,45-50 Marcovich) auf seine um 150 n.Chr. entstandene Apologie hin. Bedenkt man die Abwesenheit Justins von Rom in der Zwischenzeit, so ergibt sich für den Dialog eine Abfassungszeit nach 155 n.Chr.

23 Dieses durch Maximos Confessor einem Ariston von Pella zugeschriebene exegetische Streitgespräch zwischen einem alexandrinischen Judenchristen und einem Juden ist nur fragmentarisch überliefert (Disputatio Iasonis et Papisci, ed. J.K.T. Otto, Jena 1872). Anders als Justins Dialog mit dem Juden Tryphon scheint es sich über Jahrhunderte großer Verbreitung und Beliebtheit erfreut zu haben. Die Zuschreibung an Lukas durch Clemens von Alexandrien ist zweifellos falsch, bezeugt aber das hohe Alter und Ansehen des Werkes (vgl. Max., schol. myst. 1,3 [PG 4, 421f. Corder]). Ob Justin den zwischen 135 und 178 wahrscheinlich in Alexandrien entstandenen Dialog gekannt und benutzt hat oder nicht, bleibt mangels Indizien unklar.

24 H. Schreckenberg, Die christlichen Adversus-Judaeos-Texte und ihr literarisches und historisches Umfeld, [vol. 1.] 1.-11. Jh., EHS.T 172, Frankfurt ${ }^{2} 1990,183$.

25 Vgl. die Zusammenfassung der Forschungsdiskussion bei A. Rudolph, „Denn wir sind jenes Volk ...“. Die neue Gottesverehrung in Justins Dialog mit dem Juden Tryphon in historisch-theologischer Sicht, Hereditas 15, Bonn 1999, 67-74. 
Aufbau seines Werkes vorweg und begründet sie. Er hat sein Werk also offenbar ganz bewusst so strukturiert, dass zwei unterschiedliche Dialogformen darin miteinander verknüpft werden, oder besser gesagt: dass die eine Dialogform die andere ablöst.

\section{Vom platonischen Elenktikos ...}

Die Kapitel 1-11 stellen eine Art Präludium zum eigentlichen Dialog dar, das für das Gesamtverständnis konstitutiv ist. Schon mit dem ersten Satz wird dem Leser das für einen philosophischen Dialog typische Gattungsszenario vor Augen gemalt: Man sieht Justin an einem Morgen durch eine

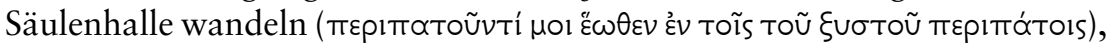
als er von Tryphon und dessen Begleitern als Philosoph angesprochen

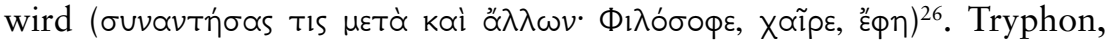
ein philosophisch interessierter Jude, eröffnet das Gespräch in der Hoffnung, aus einer Unterhaltung mit dem - bis zu diesem Zeitpunkt noch nicht als Christen enttarnten - Philosophen Nutzen ziehen zu können. Ausgelöst von der Frage Tryphons, welche Meinung ( $\gamma \nu \omega \mu \eta \dot{)})$ er von Gott und der Philosophie habe, hebt Justin zu einem Eingangsmonolog an, in dem er eine auf die biblischen Propheten gegründete christliche Lehre als die wahre Philosophie darstellt (Dialog mit dem Juden Tryphon 2,1-8,3). Zunächst berichtet Justin von seiner langen und enttäuschenden Irrfahrt durch die verschiedenen Philosophenschulen seiner Zeit - Stoiker, Peripatetiker, Pythagoräer, Platoniker -, die ihn schließlich zum Platoniker werden lässt, der die Hoffnung hegt, Gott unmittelbar schauen zu können (Dialog mit dem Juden Tryphon 2$)^{27}$. Zufällig trifft er während eines meditativen

26 Just., dial. 1,1 (69,1f. M.).

27 Es wurde viel darüber nachgedacht, ob dieser Bericht als autobiographisches Zeugnis gelten kann oder als literarische Selbstinszenierung angesehen werden muss. Freilich geht diese Diskussion von einer falschen Alternative zwischen Authentizität und literarischer Darstellung aus: Andere Autoren, die eine ganz ähnliche Irrfahrt durch die spätantiken Philosophenschulen schildern, lassen zwar darauf schließen, dass der Bericht über die Suche nach der wahren Lehre in bestimmten gebildeten Kreisen zur literarischen Konvention gehörte. So findet sich das Motiv schon bei Pl., Ap. 22a-e (CUFr 146,14-147,21 Croiset), in der Spätantike bei Pseudo-Clemens (Clem. recogn. I 3-5 [GCS 51, 7,6-9,2 Rehm/ Strecker]; Hom. Clem. I 3,1-5,9 [GSC 50, 23,21-25,3 Irmscher/Pahlke]); Porph., Plot. 3 (SCBO, Plotini opera vol. 1, 3,1-5,48 Henry/Schwyzer); Lucianus, nec. 4-6 (LCL 162, 264f. Harmon); J., Vit. 2,9-12 (CUFr, 2,13-3,3 Pelletier); vgl. auch Ps.-Just., coh. Gr. 2-7 (PTS 32, 24,1-32,25 Marcovich). Justins Schüler Tatian schildert seine Konversion von der heidnischen Bildungselite zum Christentum in ähnlicher Weise wie Justin, vgl. Tat., orat. 29,1 (PTS 43, 55,1-8 Marcovich). Dies lässt aber noch nicht den Schluss zu, dass Irrwege durch die Philosophenschulen nicht tatsächlich zur Biographie eines spätantiken Gebildeten gehört hätten: „Das Stereotype in dieser ,Literatur' rührt in erster Linie vom Stereotypen im realen Leben her." (P. Lampe, Die stadtrömischen Christen in den ersten beiden Jahrhunderten, WUNT 2/18, Tübingen 1987, 223). Vgl. M.J. Edwards, On the Platonic schooling of Justin Martyr, JThS N.S. 42, 1991, 17-34. Eine meisterhafte satirische Verarbeitung dieser Realität schuf Lukian von Samosata in seinem Werk Vitarum auctio (Luciani Vitarum auctio, ed. Joel B. Itzkowitz, BSGRT, Stuttgart 1992). 
Spaziergangs am Meer auf einen Greis, der ihn in ein Gespräch darüber verwickelt, ob die Philosophie zur Glückseligkeit verhelfen könne ( $\tilde{\eta}$ oũv

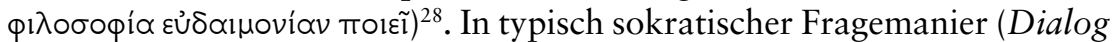
mit dem Juden Tryphon 3-5) führt der Alte das Vertrauen Justins in die platonische Gottesschau ad absurdum, um ihm dann die biblischen Propheten als die eigentlichen Künder der Wahrheit ans Herz zu legen. Diese Wahrheit findet Justin in der Lehre Jesu Christi, die er fortan als „einzige

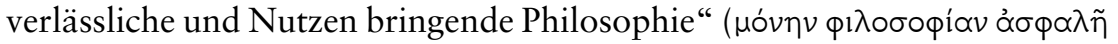

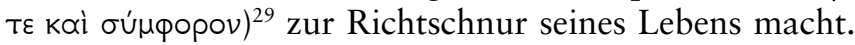

Vielfach wurde wegen des für philosophische Dialoge typischen Beginns nach Parallelen zu anderen antiken Dialogen gesucht. So fand man Anklänge an die platonischen Dialoge Politeia, Protagoras und Phaidros, an die unechten platonischen Dialoge Axiochos und Eryxias oder auch an den Lucullus Ciceros $^{30}$. Eine eindeutige Vorlage konnte unter diesen Beispielen jedoch bisher nicht überzeugend ausgemacht werden - die Unterschiede sind in jedem der Beispiele ebenso zahlreich wie die Gemeinsamkeiten -, was darauf hindeutet, dass Justin sich nicht an einen konkreten Dialog anlehnt, sondern ganz allgemein in die literarische Tradition philosophischer Dialoge stellt und sein Werk mit einzelnen konkreten Anspielungen auf klassische Texte schmückt. Auffallenderweise finden sich die Parallelen zu und Zitate aus klassischen Werken ausschließlich in der Rahmung des Dialogs und im so genannten Vorgespräch, dem Dialog Justins mit dem Greis $^{31}$. Dieser „Dialog im Dialog“ (Dialog mit dem Juden Tryphon 3-7) folgt der elenktischen Gesprächstaktik, derer sich auch Sokrates in den Dialogen Platons häufig bedient. Durch gezieltes Fragen wird Justin von

28 Just., dial. 3,4 (74,30 M.).

29 Just., dial. 8,1 (84,5f. M.).

30 Vgl. Voss, Dialog (wie Anm. 1), 26-28. In der Forschung wurde vor allem die Ähnlichkeit zu (echten und unechten) platonischen Dialogen betont, so von K. Hubik, Die Apologien des Hl. Justinus des Philosophen und Märtyrers. Literarhistorische Untersuchungen, ThSLG 19, Wien 1912; P. Keseling, Justins ,Dialog gegen Trypho' (c.1-10) und Platons ,Protagoras', RMP N.F. 75, 1926, 223-229; W. Schmid, Die Textüberlieferung der Apologie des Justin, ZNW 40, 1941, 87-138; Edwards, On the Platonic schooling (wie Anm. 27); T. Rajak, The Jewish Dialogue with Greece and Rome. Studies in cultural and social interaction, AGJU 48, Leiden 2001, 511. Vgl. aber die Kritik bei N. Hyldahl, Philosophie und Christentum. Eine Interpretation der Einleitung zum Dialog Justins, AThD 9, Kopenhagen 1966; Külzer, Disputationes graecae (wie Anm. 1), $101 \mathrm{f}$.

31 Die Lokalisierung des Gesprächs in der Säulenhalle des Xystus in Just., dial. 1,1 (69,1 M.) erinnert an Cic., ac. I 9 (PhB 479, 24,8f. Schäublin) und Cic., Brut. 10,39 (CUFr, 13,2514,6 Martha); die Seefahrt Justins als Anlass zur Unterbrechung des Gesprächs in Just., dial. 142,1-3 (314,1-19 M.) an Cic., ac. I 9.147f. (12-14.190-192 S.). Justin fragt Tryphon in dial. 1,3 (69,13 M.) mit einem Homerzitat nach seiner Identität: „Wer aber bist du,

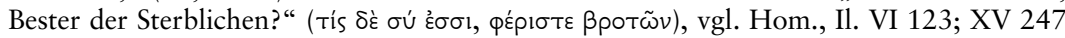
(Bibliotheca Weidmanniana 2, 109,23; 286,26 van Thiel), seine Sehnsucht nach philosophischer Ruhe beschreibt Justin ebenfalls mit einer Anspielung auf die Ilias: „völlige

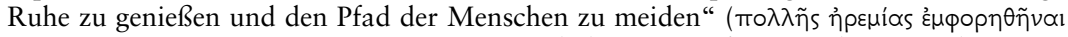

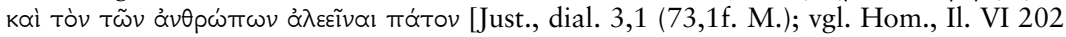
$(129,7$ v.T.)]). In dial. 5,4 (80,25-28 M.) legt Justin dem Greis ein Zitat aus Platons Timaios (Pl., Ti. 41b,2-6 [CUFr 156,16-20 Rivaud]) in den Mund. 
dem Greis nach und nach zu der Einsicht geführt, dass seine bei den Platonikern erworbenen Erkenntnisse bei der Frage nach der Glückseligkeit zu keinem Ziel führen. Die platonische Philosophie wird auf platonische Weise widerlegt ${ }^{32}$. Sie ist zwar die beste der bestehenden Philosophenschulen, aber als solche nur eine Vorbereitung auf die einzig verlässliche, die christliche Philosophie.

\section{... zum exegetischen Lehrgespräch}

Dass diese neue, auf Offenbarung beruhende Lehre sich einer anderen Art der Gesprächsführung bedient, ist die naheliegende Konsequenz aus dem Ergebnis des Gesprächs mit dem Greis. Hier wird der auf platonische Weise zum Christentum überführte Justin nun zum Lehrer, der seine Zuhörer bzw. Leser durch lange monologische Auslegungen der Prophetentexte hindurch in die christliche Wahrheit einweist.

Auf den Aufruf Justins, Tryphon möge sich ebenfalls dieser Lehre anschließen, entgegnet dieser seinerseits mit einer missionarischen Gegenoffensive: Justin solle sich an das jüdische Zeremonialgesetz halten und dem Christentum den Rücken kehren (Dialog mit dem Juden Tryphon 8,3f.). Justin wiederum bietet Tryphon an, ihn über die Wahrheit des Christentums zu belehren (Dialog mit dem Juden Tryphon 9,1), und eröffnet damit den eigentlichen Dialog. Man wählt als neuen Ort für die Disputation das Stadium des Xystus und verständigt sich zunächst über die Vorwürfe der Juden gegen die Christen - die sich von den populären Vorwürfen der Heiden wie Verzehr von Menschenfleisch oder Inzest wesentlich unterscheiden und ausschließlich das Christusbekenntnis und den Verzicht auf die Gesetzesobservanz betreffen ${ }^{33}$-, bevor Justin einen kurzen Abriss der christlichen Lehre gibt (Dialog mit dem Juden Tryphon 11). Dieses 11. Kapitel dient zugleich als Einleitung in das darauf folgende lange Gespräch (Dialog mit dem Juden Tryphon 12-142). Drei Hauptthemen werden genannt: die vorübergehende Gültigkeit des Gesetzes und die Ablösung des alten Bundes durch den neuen, von Christus gestifteten universellen Bund (Dialog mit dem Juden Tryphon 11,2f.), Jesus Christus als der von den Propheten verheißene Messias (11,3f.), und das Christentum als das wahre, geistige Israel $(11,5)$.

32 Vgl. Edwards, On the Platonic schooling (wie Anm. 27), 20: „Justins most ingenious sroke of art is that he goes on to disown the form that he imitates so well." Voss, Dialog (wie Anm. 1), 29: „Wie der Platonismus sokratischem Fragen seinen Ursprung verdankt, so wird er hier, nachdem er sich von seinem Grundprinzip entfernt hatte, eben diesem Fragen unterzogen und auf dieselbe Weise aufgehoben, wie er seine Widersacher aufgehoben hatte." Ähnlich S. Denning-Bolle, Christian Dialogue as apologetic: The case of Justin Martyr seen in historical context, Bulletin of the John Rylands Library of Manchester 69/2, 1987, (492-510) 501.

33 Just., dial. 10,1-3 (86,1-87,23 M.). 
Alle Versuche, das Gespräch zwischen Tryphon und Justin (Dialog mit dem Juden Tryphon 12-141) anhand dieser Themen oder anderer Merkmale zu gliedern, führen zu keinem zufriedenstellenden Ergebnis. Kaum zwei Forscher schlagen die gleiche Gliederung vor, obwohl man sich in der inhaltlichen Bestimmung der drei Hauptthemen weitgehend einig ist ${ }^{34}$. Der Grund für das Scheitern detaillierter Gliederungsversuche liegt darin, dass sich das Gespräch nicht progressiv entwickelt, sondern in einem komplexen Geflecht die verschiedenen Argumente und Schriftstellen exegetisch meditiert. Zwar bezeichnet Justin das Gespräch immer wieder als Beweisführung ${ }^{35}$, er entwickelt jedoch keine klar abgrenzbaren systematischen Argumentationszusammenhänge, sondern expliziert die drei in Kapitel 11 genannten Hauptthesen anhand prophetischer Schriftstellen. Einzelne zusammenhängende Exegesen ${ }^{36}$ sowie ein engmaschiges Geflecht von vorausschauenden und rückblickenden Bemerkungen ${ }^{37}$ erleichtern zwar die Orientierung im Dialog, ermöglichen aber keine scharfe Abgrenzung einzelner Gedankengänge. Justin selbst setzt diese Art der Gesprächsführung ganz bewusst ein und begründet sie auch:

Wenn ich dies auch jetzt zu euch sage, obwohl ich mich schon oft wiederholt

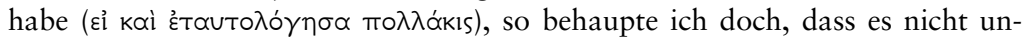
sinnig ist. Wir sehen doch die Sonne, den Mond und die anderen Sterne, wie sie immer die gleiche Bahn ziehen und die gleiche Wiederkehr der Jahreszeiten bewirken; oder den Rechenlehrer, der, wenn er gefragt wird, was zwei mal zwei

34 Vgl. die tabellarische Auflistung verschiedener Gliederungsvorschläge bei Rudolph, „Denn wir sind jenes Volk ..." (wie Anm. 25), 74; P. Bobichon, Justin Martyr, Dialogue avec Tryphon. Édition critique, traduction, commentaire, Par. 47, Freiburg 2003, 20. Rudolph versucht, als Gliederungsmerkmal nicht inhaltliche Gesichtspunkte, sondern den „Wechsel der literarischen Gattung“ heranzuziehen (S. 81). Von einem Gattungswechsel im strengen Sinn kann zwar sicherlich nicht die Rede sein. Dennoch ist es angesichts des meditativ-digressiven Charakters der ganzen Schrift sinnvoll, sich stärker an der Dynamik des Gesprächsverlaufs als an inhaltlichen Themenbereichen zu orientieren.

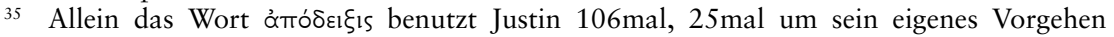
zu beschreiben. Die geforderte Verstandestätigkeit bezeichnet er mit Verben wie vociv,

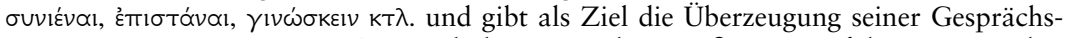

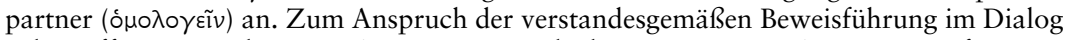
vgl. Hoffmann, Dialog (wie Anm. 1), 26; Bobichon, Justin (wie Anm. 34), 24f. Dieser Anspruch scheint zunächst in Spannung zu der Aussage des Greises zu stehen, die Propheten hätten auf Beweisführungen verzichtet und seien dennoch glaubwürdige Zeugen

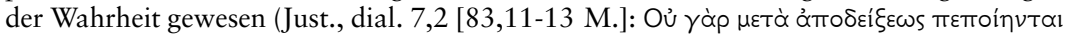

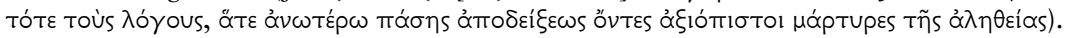
Die Notwendigkeit einer rationalen Begründung des Glaubens ergibt sich erst bei der Auslegung ihrer Schriften in der Konfrontation mit anderen Wahrheitsansprüchen. Der Appell Justins: „Werdet doch verständig, sofern ihr den Verstand bei der Sache habt!“ ( als Motto für den gesamten Dialog verstanden werden.

36 Größere zusammenhängende Exegesen gibt Justin z.B. in dial. 97-108 zu Ps 22 und zu Gen 49,8-12 in dial. 52-54.

37 Rück- und Vorausblicke finden sich in dial. 11,5; 28,1; 36,2; 39,7f.; 42,4; 43,3; 45,1.3; 48,1; 50,1f.; 55,1; 56,4.11; 57,4; 60,3; 63,1f.; 64,3.7; 66,1; 67,5; 68,9; 71,3; 77,1f.; 90,$5 ; 98,1 ; 100,1.5 ; 104,1 ; 105,1 ; 116,1 ; 118,1 ; 123,1 ; 123,7 ; 125,5 ; 129,1 ; 130,1.3$; 134,$6 ; 137,3 f$. 
ist, immer wieder, vier' antworten wird, sooft er gefragt wird und obwohl er schon mehrfach die Antwort, vier' gegeben hat; und alle anderen Dinge, die mit Bestimmtheit behauptet werden und immer wieder auf die gleiche Weise gesagt und behauptet werden. Da wäre es doch lächerlich ( $\gamma \varepsilon \lambda$ iõov $\mu \dot{\varepsilon} \nu ~ \gamma \grave{\alpha} \rho \pi \rho \tilde{\gamma} \gamma \mu \alpha$ है $\left.\sigma \tau_{\alpha 1}\right)$, wenn derjenige, der die prophetischen Schriften auslegt, nicht immer wieder dieselben Schriften zitieren würde, sondern glaubte, er könne besseres

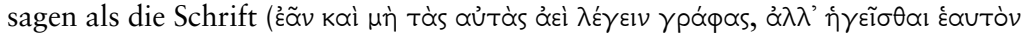

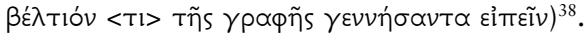

Hinter der Sammlung und Wiederholung von Schriftzitaten steht also die Überzeugung, dass die heiligen Texte immer und immer wieder gelesen und gedeutet werden müssen, bis sich ihr Sinn in ihrer ganzen Tiefe erschließt ${ }^{39}$. Justin ist sich zwar dessen bewusst, dass dieses Vorgehen für die Leser ermüdend sein könnte ${ }^{40}$. Gleichzeitig aber scheint er zu hoffen, die Leser könnten sich dem zustimmenden Urteil anschließen, das er seinen jüdischen Zuhörern für dieses Vorgehen in den Mund legt:

Einer von denen, die sich erst am zweiten Tag eingefunden hatten, Mnaseas mit Namen, sagte: „Uns freut es, dass du unsertwegen wiederholen willst“"

„Du sollst wissen, dass ich und meine Genossen uns freuen, dich zu hören, wenn du auch öfter das gleiche wiederholst" ${ }^{\text {42 }}$.

Abschweifungen, überraschende Neuansätze und Wiederholungen konnten in der Antike durchaus als rhetorische Kunstmittel gelten, wenn der Autor damit die Aneignung philosophischer Lehren durch seine Leser bezweck$\mathrm{te}^{43}$. Clemens von Alexandrien etwa begründete die lockere Komposition der Stromateis damit, dass die Wahrheit sich nur dem Leser erschließe, der sie ,aufgespürt und mit harter Arbeit erkämpft“ habe wie ein Jäger, der die Fährten seines Jagdtiers lange Zeit verfolgt, bevor er es erlegt ${ }^{44}$. In ähnlicher Weise dient auch die scheinbare Systemlosigkeit des Dialogs mit

38 Just., dial. 85,5 (217,28-37 M.).

39 Vgl. auch Lampe, Die stadtrömischen Christen (wie Anm. 27), 131-333.

40 So erspart er etwa den Lesern in Just., dial. 56,18; 128,1 (165,118f.; 292,1-4 M.) die Wiederholung bereits angeführter Zitate, obwohl er sie Tryphon und seinen Begleitern gegenüber wiederholt haben will.

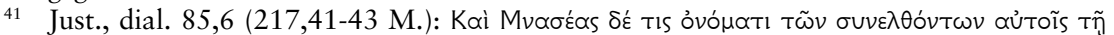

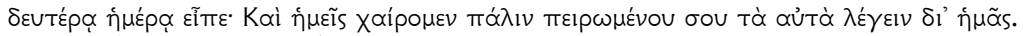

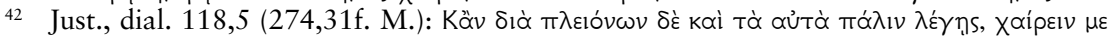

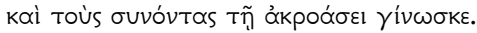

43 Arbeiten zu Seneca (I. Hadot, Seneca und die griechisch-römische Tradition der Seelenleitung, QSGP 13, Berlin 1969, 37f.) und Horaz (U. Knoche, Horazens Kunst der satirischen Gesprächsführung, in: D. Korzeniewski [Hg.], Die römische Satire, WdF 238, Darmstadt 1970, 284-319) haben den psychagogischen Aspekt von Digressionen, überraschenden Neueinsätzen und Wiederholungen betont. Die scheinbare Systemlosigkeit philosophischer Werke ist häufig in der Orientierung an der Seelenleitung begründet. Vgl. die exemplarische stilistische Analyse von Just., dial. 1 durch H.F. Stander, Is Justin Really a Bad Stylist?, SecCen 86, 5/4, 1985/1986, 226-232, sowie Lampe, Die stadtrömischen Christen (wie Anm. 27), 232.

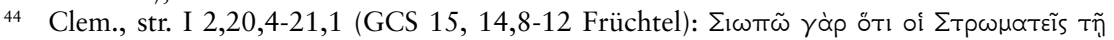

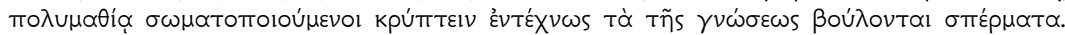

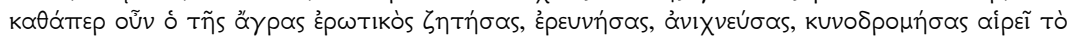


dem Juden Tryphon der exercitatio animi, der meditierenden Einübung christlicher Schriftauslegung. Der Dialog zeigt nicht nur den Weg zur Wahrheit, er will selbst ein solcher Weg sein. Im Verlauf des Gesprächs zwischen Tryphon und Justin lässt sich deshalb auch eine Entwicklung vom freundlich gehaltenen Beginn über ein konfrontatives Wortgefecht bis zur monologischen Unterweisung Tryphons und seiner Begleiter durch Justin beobachten ${ }^{45}$. Der Dialog will selbst ein exegetischer Übungsweg sein, will in zahlreichen Wiederholungen und Exkursen die richtige Auslegung der Prophetenschriften mit seinen Lesern einüben.

Die literarische Form des Dialogs spiegelt die grundlegende inhaltliche Aussage wider. Während im Einleitungsteil (Dialog mit dem Juden Tryphon 1-11) mit der kurzen Widerlegung der platonischen Philosophie die Grundlage für die Zuwendung zur christlichen Offenbarung gelegt wird, bietet der Hauptteil (Dialog mit dem Juden Tryphon 12-142) eine umfassende Einweisung in die christliche Lehre. Entsprechend ist das Gespräch Justins mit dem unbekannten Greis (Dialog mit dem Juden Tryphon 3-8) als maieutisch-elenktischer Dialog gestaltet, das Gespräch mit Tryphon als monologisches Lehrgespräch mit dialogischen Elementen ${ }^{46}$. Durch den Wechsel der Dialogform verleiht Justin seiner inhaltlichen These, dass das auf Offenbarung der Wahrheit basierende Christentum „die einzige verlässliche und Nutzen bringende Philosophie “47 sei, auch formal Gestalt.

In welchen realen Diskurs seiner Zeit will Justin damit eingreifen? Die These von der Dekadenz der Philosophie und ihrer Vertreter, die sich auch in Justins Klage über die in Schulen aufgespaltene Philosophie seiner Zeit niederschlägt ${ }^{48}$, veranlasste vor allem mittelplatonische Philosophen zur Suche nach - möglichst alten und orientalischen - Autoritäten, die eine Kontinuität mit der „Urphilosophie ${ }^{\text {“49 }}$ garantierten $^{50}$. Justin wird durch den unbekannten Greis auf die biblischen Propheten und ihre Lehre auf-

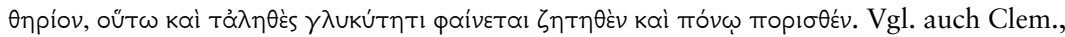
str. I 12,56,3 (37,9-12 F.).

45 Auf diese Dynamik machten Hubik, Apologien (wie Anm. 30), 32-36, und Rudolph, „Denn wir sind jenes Volk“ (wie Anm. 27), 66-82 aufmerksam. In der Abgrenzung der Textteile aber divergieren beide voneinander ebenso wie in der Charakterisierung: Hubik sah in Just., dial. 11-31 einen ruhigen, freundschaftlichen Ton vorherrschen, der in dial. 32-110 in „Kampf und Verteidigung“ umschlage und schließlich in dial. 111-136 einer „resignierten Ruhe“ weiche. Rudolph dagegen unterschied zwischen dial. 12-96 bzw. 108 als einem „echten Dialog“ und dial. 97 bzw. dial. 110-142 als Monolog Justins.

46 Diese im Grunde monologische Dialogform war zu Justins Zeit in Mode: „Late antiquity preferred the dialogues of Platos middle period, in which the principal speaker delivers his thought in long orations, pausing but seldom and briefly either for question or for assent." (Edwards, On the Platonic schooling [wie Anm. 27], 18).

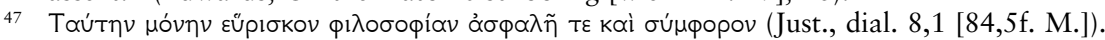

48 Just., dial. 2,1f. (71,1-72,14 M.).

49 Diesen Begriff verwendet Hyldahl, Philosophie (wie Anm. 30), 112-140.

50 Eine Dekadenztheorie vertraten Poseidonios von Apamea, Antiochos von Askalon, Attikos, Apuleios und Numenios von Apamea. Siehe dazu Hyldahl, Philosophie (wie Anm. 30); A.J. Droge, Justin Martyr and the Restoration of Philosophy, ChH 56, 1987, 303-319; R.M. Grant, The Letter and the Spirit, London 1957, 18-30. 
merksam und erkennt in ihnen die - alten und orientalischen - Autoritäten und die Wahrheit, die allen philosophischen Lehren zu Grunde liegt und zugleich deren Ziel ist. Im Vergleich mit ihnen sind die Lehrautoritäten,

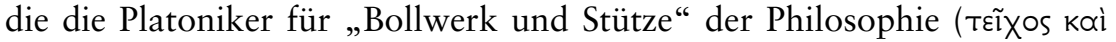

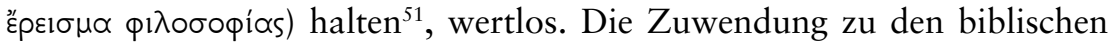
Propheten ist Justins Antwort auf die philosophische Frage, die sich aus der unter Mittelplatonikern populären These von der Dekadenz der Philosophie durch die Aufspaltung in verschiedene Schulen ergab. Sind die Autoritäten der Urphilosophie gefunden, dann kann es keine andere Methode zur Erforschung der Wahrheit geben als eine Einweisung in ihre vom göttlichen Geist inspirierten Schriften. Die Wahrheit erweist sich nun nicht mehr in der rationalen Beweisführung eines sokratischen Gesprächs, sondern durch die Einsicht, dass sich die alten Weissagungen in der Geschichte bewahrheitet haben $^{52}$. Der Dialog dient dann nicht mehr der Wahrheitssuche, sondern dem denkenden Nachvollzug einer als Wahrheit erkannten Lehre, im Falle Justins durch Auslegung der Offenbarungsschriften.

Indem Justin die vertraute Form des elenktischen Gesprächs nach kurzer Zeit in eine andere, neue Form überführt, gibt er seiner These, dass das Christentum Erfüllung sowohl der griechischen Philosophie als auch der in alter Vorzeit gegebenen jüdischen Verheißungen ist - also einer Verbindung dessen, was für religiöse Sucher seiner Zeit anziehend war -, literarische Gestalt. Die literarische wie theologische Innovation besteht darin, dass Justin als erster (und einziger) Christ die Auseinandersetzung mit der klassischen literarischen Dialogtradition mit einer neuen, vom realen exegetischen Streitgespräch mit jüdischen Schriftgelehrten inspirierten Form des Dialogs verband.

\section{Der Octavius des Minucius Felix}

Die zweite christliche Transformation des klassischen philosophischen Dialogs hat der aus Afrika stammende Anwalt (causidicus) Marcus Minucius Felix einige Jahrzehnte nach Justin, in der ersten Hälfte des 3. Jahrhunderts und wahrscheinlich wie Justin in Rom, mit seinem Octavius geschaffen ${ }^{53}$.

51 Just., dial. 5,6 (81,43 M.).

52 Die Bewahrheitung der Schrift in der Geschichte ist das entscheidende Wahrheitskriterium für Justin, vgl. Just., dial. 7,2 (83,13f. M.): „Die Geschichte der Vergangenheit und Gegenwart ist es, welche zwingt, ihren (scil. der Propheten) Worten zuzustimmen " (тஷ丿

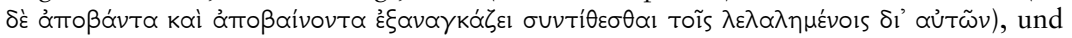
dial. 28,2 (114,5-115,7 M.): „Ich gehe in meinen Beweisen und Darlegungen von der Schrift und der Geschichte aus; darum zögert und zaudert nicht, mir Glauben zu schen-

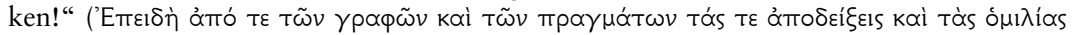

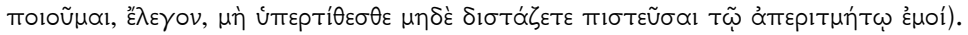

53 Zitate folgen der Edition von B. Kytzler (M. Minuci Felicis Octavius, edidit Bernhard Kytzler, BSGRT, editio correcta, Stuttgart 1992). Die Datierung des Octavius war lange Zeit heftig umstritten. Seitdem die Prioritätsfrage zwischen Minucius Felix und Tertullian 
Über Autor und Werk ließe sich das genaue Gegenteil von Justin und seinem Dialog mit dem Juden Tryphon sagen: Galt Justin als geschätzter Apologet, unter dessen Namen viele Werke kursierten, so war Minucius Felix als Person lange Zeit unbekannt, so dass man seinen Octavius zunächst für das achte Buch (octavus) Ad nationes des Arnobius von Sicca hielt. Bezeichnete man Justins Dialog mit dem Juden Tryphon bisweilen als sprachlich minderwertig, aber theologisch gehaltvoll, so gilt der $\mathrm{Oc}$ tavius des Minucius Felix als stilistisches Meisterwerk, das jedoch „jedes tiefergehende Verständnis des Christentums vermissen “ lasse ${ }^{54}$. Besonders auffällig ist, dass Minucius - wiederum in krassem Gegensatz zu Justin - in seinem Dialog kein einziges Bibelzitat anführt und auch auf die Darlegung christlicher Glaubensinhalte weitgehend verzichtet ${ }^{55}$, was ihm in der älteren Forschung den (sicherlich unzutreffenden) Vorwurf eingebracht hat, ein defizitärer Christ zu sein ${ }^{56}$. Die Zurückhaltung im Rückgriff auf christliches Traditionsgut erklärt sich jedoch ganz einfach aus dem Gesichtsfeld des Dialogs: Anders als Justin beschreibt Minucius Felix nicht das Gespräch zwischen einem Christen und einem Juden über die Auslegung der biblischen Schriften, sondern ein Streitgespräch zwischen einem Christen und einem Heiden über die wahre Religion (vera religio). Da zwischen Heiden und Christen kein Einverständnis im Blick auf die Autorität heiliger

zugunsten des letzteren geklärt ist, kann zumindest das Erscheinungsjahr des Apologeticum (197 n.Chr.) als terminus post quem als gesichert gelten. Die neuere Forschung datiert das Werk recht einhellig in das erste Drittel des 3. Jahrhunderts, vgl. zuletzt ausführlich: M. v. Albrecht, M. Minucius Felix as a Christian Humanist, Illinois Classical Studies 12/1, 1987, 157-168.

54 L.W. Barnard, Art. Apologetik, TRE 3, 1978, (371-411) 402; ähnlich im Urteil auch B. Kytzler, Art. Minucius Felix, TRE 23, 1994, (1-3) 2; J. Flamant, Die Anfänge der lateinischen christlichen Literatur, in: L. Pietri (Hg.), Die Geschichte des Christentums, Bd. 1. Die Zeit des Anfangs (bis 250), Freiburg/Basel/Wien 2003, (942-960) 954. Zu einem gänzlich anderen Urteil kommt überzeugend B. Aland, Christentum, Bildung und römische Oberschicht. Zum „Octavius“ des Minucius Felix, in: H.-D. Blume/F. Mann (Hgg.), Platonismus und Christentum. Festschrift für Heinrich Dörrie, JAC.E 10, Münster 1983, 11-30.

55 Als eindeutig christliche Elemente können nur die Darstellung der christlichen Auferstehungshoffnung (Min. Fel., Oct. 34,6-12 [BSGRT, 32,20-33,19 Kytzler]) und die Verteidigung des Kreuzsymbols (Min. Fel., Oct. 29,2-8 [28,15-36 K.]) gelten. Darüber hinaus finden sich jedoch einige biblisch inspirierte Formulierungen, vgl. dazu die entsprechenden Indices in der Ausgabe von G.W. Clarke, The Octavius of Marcus Minucius Felix, translated and annotated by G.W. Clarke, ACW 39, New York 1974, 381. Die kürzlich von C. Schubert vorgetragene These, die Rede des Octavius sei nach dem Vorbild von Röm 1f. gestaltet, besticht auf den ersten Blick durch Originalität, hält jedoch einer eingehenderen Überprüfung am Text m.E. nicht stand (C. Schubert, Biblische Spuren bei Minucius Felix, in: F.R. Prostmeier [Hg.], Frühchristentum und Kultur, Kommentar zu frühchristlichen Apologeten. Ergänzungsband 2, Freiburg 2007, 237-248).

56 So sah etwa R. Kühn, Der Octavius des Minucius Felix. Eine heidnisch-philosophische Auffassung vom Christentum, Leipzig 1882, 62f. in Minucius einen Neophyten, der im Grunde noch ganz dem Heidentum verhaftet gewesen sei. Andere Forscher glaubten in ihm einen Häretiker mit monarchianistischer Christologie vor sich zu haben, vgl. A. Baehrens, M. Minucii Felicis Octavius, Leipzig 1886, XII-XIV; H. Dessau, Minucius Felix und Caecilius Natalis, Hermes 40 (1905), 373-386. 
Schriften bestand, musste Minucius die Auseinandersetzung vollkommen anders angehen. Anstelle von Bibelzitaten bietet er daher eine Vielzahl von Anspielungen auf die heidnische philosophische und literarische Tradition, weshalb Hieronymus ihn als Kenner der gesamten lateinischen Literatur pries $^{57}$. Neuzeitliche Forscher, die die von Minucius verarbeiteten Quellen aufdeckten, warfen ihm wegen der Vielzahl der Bezüge freilich Beliebigkeit vor. Aus willkürlich zusammengesetzten Elementen der klassischen Tradition (Cicero, Platon, Seneca, Fronto, Sallust, Valerius Maximus, Florus, Tacitus, Sueton, Aulus Gellius, Apuleius, Homer, Ennius, Lukrez, Catull, Juvenal, Vergil) und der christlichen Apologetik (Tertullian, Clemens von Alexandrien, Athenagoras, Justin, Tatian, Theophilus von Antiochien, Aristides) $)^{58}$, so die Kritik, füge Minucius in seinem Octavius ein Mosaik zusammen, dem jede theologische Innovation und Eigenständigkeit fehle ${ }^{59}$. In der neueren Forschung wurde dagegen zunehmend die Eigenständigkeit des Minucius im Umgang mit der Tradition betont: Die Frage ist nicht mehr, ob und welche Traditionen Minucius aufnimmt, sondern wie er mit ihnen umgeht ${ }^{60}$. Und gerade hier, in seinem Umgang mit Quellen und Traditionen, beweist Minucius seine Originalität ${ }^{61}$. Während dieser Aspekt in den Analysen bisher zumeist an kleineren Einheiten und wörtlichen Zitaten innerhalb des Dialogs aufgezeigt worden ist, sollen hier die literarische Form und die gesamte Komposition des Werkes im Vordergrund stehen. Der Octavius kann nämlich als christliche Transformation der skeptischen Methode gelesen werden, wie Minucius sie aus Ciceros De natura deorum, aber auch aus zeitgenössischen Werken kannte. Dass Minucius De natura deorum gekannt und benutzt hat, ist unzweifelhaft - Octavius 19,3-20,1 bieten eine genaue Replik auf De natura deorum 1,10,25-16,42. Die Bezugnahme reicht jedoch weit über diese Stelle hinaus.

\section{Von der skeptischen Methode ...}

Der Octavius ist, wiederum im Gegensatz zu Justins Dialog mit Tryphon, sehr klar gegliedert: Octavius 1-4 Einleitung, 5-13 Rede des Caecilius, 14f. Zwischengespräch, 16-38 Rede des Octavius, 39f. Schluss. Minucius bettet

57 Vgl. Hier., epist. 70,5,1 (CSEL 54, 707,6-9 Hilberg): quid gentilium litterarum dimisit intactum?.

$58 \mathrm{Zu}$ den Quellen des Octavius vgl. ausführlich C. Ingremeau, Minucius Felix et ses sources. Le travail de l'écrivain, REAug 45, 1999, 3-20.

59 So vor allem das Urteil der älteren französischen Forschung, vgl. stellvertretend J. Beaujeu, Introduction, in: Minucius Felix, Octavius, texte établi et traduit par Jean Beaujeu, CUFr, Paris ${ }^{2} 1974$, XCIIIf.

60 Wegweisend für diesen Wandel waren die Monographie von C. Becker, Der „Octavius“ des Minucius Felix. Heidnische Philosophie und frühchristliche Apologetik, ABAW.PH 1967/2, München 1967, sowie die Aufsätze von Aland, Christentum (wie Anm. 54) und Ingremeau, Minucius Felix (wie Anm. 58).

61 Besonders betont von Aland, Christentum (wie Anm. 54); S. Deléau, Minucius Felix, Octavius 32, Via Latina 150, 1998, 44-53; Ingremeau, Minucius Felix (wie Anm. 58). 
seinen Dialog in eine warmherzige Erinnerung an seinen Freund Octavius ein (Octavius 1$)^{62}$, der noch vor Minucius selbst Christ geworden war und in einer „ausgesprochen ernsten Auseinandersetzung“ (disputatione gravissima) den gemeinsamen Freund Caecilius, „der damals noch abergläubischen Wahnvorstellungen anhing, zur wahren Religion bekehrt" habe ${ }^{63}$. Der Ausgang des Disputs ist damit von vornherein klar. Minucius will keine erzählerische Spannung erzeugen, sondern von Anfang an Aufmerksamkeit für den im Octavius geehrten Christen und seine Rede erzeugen.

Darüber, dass der Octavius ein fiktives Gespräch in fiktiver Szenerie darstellt, kann kein Zweifel bestehen. Zu deutlich sind die Anleihen, die Minucius bei der klassischen Dialogtradition macht, als dass es sich um eine protokollarische Nachschrift einer historischen Begebenheit handeln könnte. Wie in vielen philosophischen Dialogen der klassischen Tradition - und auch in Justins Gespräch mit dem unbekannten Greis (Dialog mit dem Juden Tryphon 2) - so bildet auch bei Minucius Felix das Meer den szenischen Hintergrund des Dialogs. Die drei Freunde (familiares) nutzen die Anwesenheit des Afrikaners Octavius in Rom während der Weinernteferien bei Gericht zu einem Ausflug in die Hafenstadt Ostia, wo sie sich am Zusammenspiel von Natur und Kultur ergötzen wollen. Die Idylle wird allein dadurch gestört, dass Caecilius einem Serapisstandbild im Vorübergehen eine Kusshand zuwirft, „wie es das abergläubische Volk zu tun pflegt" (ut vulgus superstitiosus solet $)^{64}$. Daraufhin erteilt Octavius dem Minucius (nicht Caecilius!) eine Rüge: Dass sein Freund wie das ungebildete Volk in Blindheit verharre, mache ihm, Minucius, mindestens ebenso viel Schande wie Caecilius selbst. Dieser Vorwurf scheint zunächst in der freundschaftlichen Atmosphäre unterzugehen, so dass sich Minucius der Schilderung eines Kinderspiels hingeben kann. Aber Caecilius ist durch den nur indirekt an ihn geäußerten Vorwurf der Unwissenheit (inscientia) verstimmt und fordert daher einen Disput mit Octavius, bei dem Minucius als Schiedsrichter (arbiter) fungieren soll (Octavius 2-4).

Mit der Frage nach den verschiedenen Lebensformen (vivendi genera) ${ }^{65}$ steht ein philosophisches Thema zur Debatte, so dass der Leser zu Recht einen philosophischen Disput erwartet. Die Disputierenden sind freilich auf dem Gebiet der Philosophie Laien: Minucius und Caecilius sind Juristen, Octavius ist „in Geschäften“ (Octavius 2,1) unterwegs. Sowohl in der Sprache als auch in der Gesamtanlage des Dialogs scheint der juristische

62 Die Eingangsworte cogitanti mibi et cum animo meo Octavi boni et fidelissimi contubernalis memoriam recensenti (Min. Fel., Oct. 1,1 [1,1f. K.]) erinnern formal an den Anfang von Cic., de orat. I 1 (BSGRT, 1,1f. Kumaniecki): cogitanti mibi saepenumero, inhaltlich durch den enkomienhaften Einstieg an den Beginn von Platons Protagoras und rufen damit die beiden wichtigsten Gewährsmänner des Minucius aus der klassischen Tradition auf.

63 Min. Fel., Oct. 1,5 (1,15f. K.): quo Caecilium superstitiosis vanitatibus etiamnunc inhaerentem disputatione gravissima ad veram religionem reformavit.

64 Min. Fel., Oct. 1,2 (2,3f. K.).

65 Min. Fel., Oct. 5,1 (3,12 K.). 
Hintergrund durch. Die philosophische disputatio in utramque partem mit propositio und responsio wird mit einer Gerichtsverhandlung mit probatio und refutatio vermischt - schon in dieser Verbindung von philosophischer und christlich-apologetischer Tradition zeigt sich die innovative Kraft des Minucius $^{66}$.

Die Diskussion folgt also dem antilogistischen Schema, wobei die Verteidigung bzw. die responsio des Octavius (Octavius 16-38) dreimal so lang ausfällt wie die Anklage bzw. propositio des Caecilius (5-13). Caecilius trägt zunächst eine skeptische Erkenntnistheorie vor $(5,2-13)$. Die einzig sinnvolle Konsequenz aus der prinzipiellen Unmöglichkeit sicherer Gotteserkenntnis, so folgert Caecilius, sei die Zuwendung zur traditionellen Religion der Väter $(6,1-8,2)$. Aus dem religiösen Traditionalismus ergibt sich eine entschiedene und in empörtem Tonfall vorgetragene Ablehnung des Christentums (8,3-12,7), das Caecilius nur als atheistischen Neuerungswahn verstehen kann. Gegen die neue philosophische Sekte führt er allerhand Vorwürfe ins Feld: „Leute aus einer kläglichen, verbotenen, hoffnungslosen Rotte“ maßten sich an, „Sturm gegen die Götter zu laufen " ${ }^{67}$, sie trieben während ihrer geheimen Kultfeiern Unzucht, sie beteten einen Eselskopf und die Genitalien der Priester an, mordeten für ihre Initiationsriten Kinder und tränken ihr Blut. Ähnlich empörend wie ihr Leben sei ihre Lehre von einem allwissenden Gott und der Auferstehung nach dem Tod. Galt die Macht Roms Caecilius als Beweis für die Wahrheit der römischen Religion, so weist er nun auf das irdische Leben der Christen, auf Verfolgung, Krankheit und Armut hin, um die Machtlosigkeit bzw. Ungerechtigkeit des christlichen Gottes zu illustrieren. Zum Ende seiner Rede kommt Caecilius noch einmal auf die anfangs thematisierte Möglichkeit der Gotteserkenntnis zurück. Der Mensch müsse sich der Spekulation über die Götter enthalten und solle vielmehr nach dem Wesen des Menschen fragen. Denn, so schließt Caecilius unter Berufung auf Sokrates, im Eingeständnis der Unwissenheit bestehe die höchste Ein$\operatorname{sich}^{68}$. Am Ende seiner Rede vertritt Caecilius allerdings eine radikalere Skepsis als zu Beginn: Hatte er zunächst nur behauptet, dass „alles nur als wahrscheinlich, nicht als wahr gelten darf" ${ }^{\text {"69 }}$, so fordert er nun, dass man „unlösbare Fragen als Fragen auf sich beruhen lassen soll und sich nicht kühn und keck auf die eine oder andere Ansicht festlegen darf “70.

66 Dass es sich um eine „bewusst gewählte Mischform“ handelt, betont auch C. Noack, Der „Octavius“ des Minucius Felix. Ein interreligiöser „Rechtsstreit“ unter Freunden zur Beurteilung der römischen und christlichen religio, Spes Christiana 17, 2006, (7-20) 9.

67 Min. Fel., Oct. 8,3 (6,30f. K.): homines deploratae inlicitae ac desperatae factionis grassari in deos.

68 Min. Fel., Oct. 13,2 (10,29f. K.): ita confessae inperitiae summa prudentia est.

69 Min. Fel., Oct. 5,2 (3,18f. K.): nullum negotium est patefacere omnia in rebus humanis dubia incerta suspensa magisque omnia verisimilia quam vera.

70 Min. Fel., Oct. 13,5 (11,7-9 K.): Mea quoque opinione, quae sunt dubia, ut sunt, relinquenda sunt, nec tot ac tantis viris deliberantibus temere et audaciter in alteram partem ferenda sententia est. 
Mit triumphierendem Lächeln beendet Caecilius seine, wie auch Minucius zugeben muss, brillant vorgetragene Rede.

Alfons Fürst hat überzeugend dargelegt, dass in Rede und Person des Heiden Caecilius zwei Formen der philosophischen Skepsis miteinander vermischt werden, die einander eigentlich ausschließen - die akademische Skepsis, die Minucius von Cicero als ein zu seiner Zeit jedoch bereits Geschichte gewordenes philosophisches Phänomen übernimmt, und die pyrrhonische Skepsis, deren wichtigster Vertreter, Sextus Empiricus, ein Zeitgenosse des Minucius gewesen ist $^{71}$. Durch die Vermischung beider Arten der Skepsis entsteht Fürst zufolge in der Figur des Caecilius ein unaufhebbarer innerer Widerspruch, an dem die Glaubwürdigkeit seiner Person und Position scheitert. Denn während für den akademischen Skeptiker wahrscheinliche und glaubhafte Aussagen möglich sind, bestreitet der pyrrhonische Skeptiker grundsätzlich jede Erkenntnisfähigkeit. Fürst zufolge überstieg dieser Widerspruch „den Horizont des fachphilosophisch mäßig versierten Minucius Felix “72, er war sich des philosophischen Widerspruchs in der Figur des Caecilius also selbst nicht bewusst.

Ist aber der Selbstwiderspruch tatsächlich eine philosophische Panne im Octavius? Ein Blick auf die Inszenierung des Dialogs lässt Zweifel an dieser Deutung aufkommen. In seiner Antwort auf Caecilius betont Octavius - und durch seinen Mund Minucius Felix selbst - die Widersprüchlichkeit in der Argumentation seines befreundeten Kontrahenten:

Es ist wie bei einem Menschen, der den richtigen Weg nicht kennt: Wenn nun, wie es ja vorkommt, die eine Straße in mehrere Arme sich teilt, bleibt er, eben weil er den Weg nicht weiß, ängstlich stehen, weder wagt er einen Pfad auszuwählen, noch kann er alle für richtig halten. Genauso schwankt das Urteil eines Menschen, der kein sicheres Kriterium zur Wahrheitsfindung besitzt, haltlos hin und her, sobald irgendeine unsichere Hypothese auftaucht. Und so ist es kein Wunder, wenn unser Caecilius immer wieder in Gegensätzen und Widersprüchen geradezu wie in der Brandung hin und her geworfen wird ${ }^{73}$.

Diese Analyse des Seelenzustandes seines agnostischen Gegenübers ist ein fundamentaler Angriff auf den Anspruch der Skeptiker, durch den Verzicht

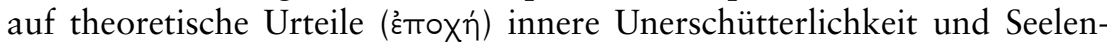

71 Vgl. die beiden Aufsätze von A. Fürst, Der philosophiegeschichtliche Ort von Minucius Felix’ Dialog „Octavius“, JAC 42, 1999, 42-49; ders., Die Selbsterkenntnis des Skeptikers im Octavius des Minucius Felix, ZAC 4, 2000, 270-281. Dass Sextus Empiricus zur Zeit des Minucius in Rom gelesen und auch von Christen rezipiert wurde, zeigt das Beispiel des Verfassers der Refutatio omnium haeresium, der sich von der dem „Grundriss der pyrrhonischen Skepsis“ zugrunde liegenden Methode des Skeptikers inspirieren ließ, vgl. L. Floridi, Sextus Empiricus. The Transmission and Recovery of Pyrrhonism, American Philological Association, American Classcial Studies 46, Oxford 2002, $5 \mathrm{f}$.

72 Fürst, Selbsterkenntnis (wie Anm. 71), 280.

73 Min. Fel., Oct. 16,3f. (12,21-26 K.): ut qui rectam viam nesci, ubi, ut fit, in plures una diffinditur, quia viam nescit, haeret anxius nec singulas audet eligere nec universas probare, sic, cui non est veri stabile iudicium, prout infida suspicio spargitur, ita eius dubia opinio dissipatur. nullum itaque miraculum est, si Caecilius identidem in contrariis ac repugnantibus iactetur aestu et fluctuetur. 


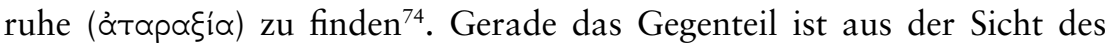
Octavius der Fall: Wer kein sicheres Wahrheitskriterium anerkennt, wird halt- und ruhelos, verirrt sich in Widersprüchen. Die Skepsis, die mit dem Anspruch auftritt, den Menschen zu heilen, macht ihn in Wahrheit krank ${ }^{75}$. Minucius war sich der Widersprüchlichkeit in der Person des Caecilius also offenbar bewusst, vielmehr: Er hat den Caecilius und seine Argumentation bewusst widersprüchlich inszeniert, um ihn besser widerlegen zu können. Der Skeptiker zerbricht an seinem Selbstwiderspruch. Bereits in der Charakterisierung der beiden Gesprächsteilnehmer setzt Minucius deutliche Akzente zugunsten des Christen: Der Heide Caecilius erscheint als hochmütig, schnell reizbar und aufbrausend, bisweilen beleidigend und jederzeit siegessicher - aber argumentativ nicht stringent ${ }^{76}$. Octavius dagegen wird dem Leser gleich zu Beginn als gutmütiger Familienvater und treuer Freund vorgestellt, seine Rede ist besonnen und sachlich ${ }^{77}$. Während Caecilius die Christen und Octavius direkt attackiert und häufig in der zweiten Person anredet, spricht Octavius mit vornehmer Distanz ausschließlich in der dritten Person über die Heiden und Caecilius. Auf diese Weise entsteht der Eindruck, dass Caecilius im Affekt redet und am Ruhm seines Erfolgs in der Disputation mehr Interesse hat als an der Wahrheit. Octavius dagegen erscheint als der urbane, gelassene Disputant, der allein der Wahrheit verpflichtet ist. Wer also mit Caecilius die Christen als „ungebildete, ungehobelte, plumpe, bäuerische Leute“ verschmäht ${ }^{78}$, muss bei der Lektüre des Dialogs den Eindruck haben, dass der Heide selbst diesem Zerrbild viel eher entspricht als der Christ.

\section{... zur christlichen eloquentia}

Aber nicht nur in der Charakterisierung der Personen, auch in der Gesamtanlage des Dialogs zwingt Minucius die Skepsis zum Selbstwiderspruch. Dies wird am Umgang mit der literarischen Vorlage des Octavius, Ciceros De natura deorum, deutlich. Darin lässt Cicero drei Philosophen miteinander über die Natur der Götter diskutieren: den Epikuräer Gaius Velleius, den Stoiker Quintus Lucius Balbus und den Skeptiker Cotta, der die eine wie die andere Götterlehre in Zweifel zieht. Minucius schreibt diese Auseinandersetzung zwischen Dogmatikern und Skeptikern im Octavius

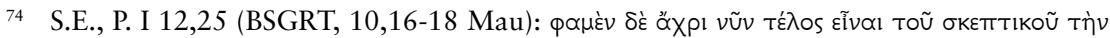

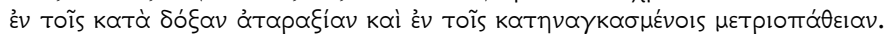

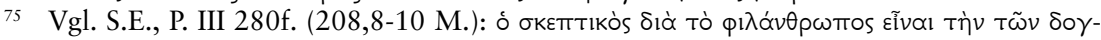

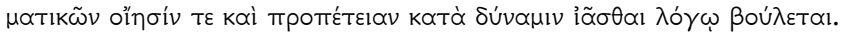

76 Vgl. Min. Fel., Oct. 4,3f. (2,35-3,3 K.); 8,3-5 (6,27-7,8 K.); 14,1 mit der Bemerkung: nam indignationis eius tumorem effusae orationis impetus relaxaverat $(11,11 \mathrm{f} . \mathrm{K}$.$) ; den$ Vorwurf gegen Minucius in 15,1 (12,5-7 K.); 40,1: Caecilius erupit (37,10 K.).

77 Siehe besonders das enkomienhafte erste Kapitel (Min. Fel., Oct. 1,1-16 K.), dann auch die in der Sache heftige, aber freundschaftlich vorgetragene Kritik an Caecilius in Oct. 16,1-4 (12,13-28 K.).

78 Min. Fel., Oct. 12,7 (10, 22 K.): indocti, impoliti, rudi, agresti. 
aktualisierend fort - die „dogmatische“ Position wird nun von einem Christen vertreten. Auffallend ist jedoch die Anordnung der Redebeiträge: Cicero lässt jeweils zuerst den Dogmatiker seine Lehre entfalten, um diese dann wirkungsvoll durch den Skeptiker widerlegen zu können. Diese Disputationsform preist er als gegenüber dem dialektischen Gespräch für den Skeptizismus angemessener ${ }^{79}$. In der pyrrhonischen Skepsis, vertreten vor allem durch den bereits erwähnten Zeitgenossen des Minucius Felix, Sextus Empiricus, wird diese Methode besonders ausgefeilt angewandt ${ }^{80}$. Danach sollten zunächst die Standpunkte einer dogmatischen Lehrmeinung zusammenhängend dargelegt und dann Punkt für Punkt in Frage gestellt werden. Minucius kehrt nun die Reihenfolge um: Der Skeptiker Caecilius stellt zuerst seine Weltsicht vor - und wird damit gezwungen, seine Ansicht in einer zusammenhängenden Rede darzustellen. Dadurch wird der Skeptiker seiner Methode beraubt und erscheint paradoxerweise selbst als Dogmatiker. Der „Dogmatiker“ Octavius kann daraufhin formal die Rolle des Skeptikers übernehmen, der seinen Gegner Punkt für Punkt widerlegt. Minucius bedient sich also für die Widerlegung der Skeptiker derselben Methode, die diese zur Widerlegung der Dogmatiker anwendeten. Der Skeptizismus, der alle dogmatischen Anschauungen zu widerlegen suchte, erscheint nun seinerseits als dogmatische Weltanschauung, die widerlegt werden kann. Damit hat Minucius seine Gegner nicht nur - wie es sein ausdrückliches Ziel war - argumentativ, sondern auch methodisch „mit ihren eigenen Waffen geschlagen“81.

Dieser literarische Kunstgriff ist besonders deshalb interessant, weil der Prozess des Verfassens aller Wahrscheinlichkeit nach gerade umgekehrt verlaufen ist. Die Analyse der Komposition der Reden zeigt, dass Minucius die Caeciliusrede auf die Widerlegung durch Octavius hin komponiert hat. Den Dreischritt, der der Octaviusrede zugrunde liegt - Darlegung des Monotheismus (Octavius 16,5-20,1), Polemik gegen den Polytheismus

79 Cic., nat. deor. I 11 (Cambridge Greek and Latin Texts, 25,34-39 Dyck): ut haec in philosophia ratio contra omnia disserendi nullamque rem aperte iudicandi, profecta a Socrate, repetita ab Arcesila, confirmata a Carneade, usque ad nostrum uiguit aetatem; quam nunc propemodum orbam esse in ipsa Graecia intellego, quod non Academiae uitio sed tarditate hominum arbitror contigisse.

80 Sextus Empiricus formuliert als programmatischen Anspruch der pyrrhonischen Skepsis, in der „speziellen Erörterung “ „jeden Teil der sogenannten Philosophie zu widerlegen“,

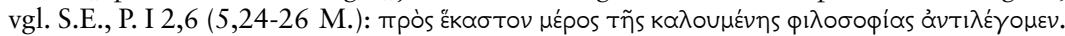
$\mathrm{Zu}$ Leben und Methode des Sextus Empiricus vgl. R. La Sala, Die Züge des Skeptikers. Der dialektische Charakter von Sextus Empiricus’ Werk, Hyp. 160, Göttingen 2005.

81 Vgl. Min. Fel., Oct. 39 (37,7f. K.): malevolos isdem illis, quibus armantur, philosophorum telis retudisset. Das ganze Kapitel 39 (37,4-9 K.), in dem Minucius Octavius rühmt, er habe „die Dinge, die man leichter fühlen als aussprechen kann, mit Argumenten, Beispielen und Zitaten aus den Schriften bekräftigt" (ea, quae facilius est sentire quam dicere, et argumentis et exemplis et lectionum auctoritatibus adornasset) und daher ,die Wahrheit nicht nur leicht fasslich, sondern zugleich anziehend dargestellt" (ostendisset veritatem non tantummodo facilem sed et favorabilem), ist ja im Grunde ein kokettes Eigenlob des Minucius für seinen Dialog. 
(20,2-27,8), Nachweis der ethischen Unversehrtheit der Christen (28,1$38,4)$ - übernahm Minucius von den griechischen Apologeten ${ }^{82}$. Die Caeciliusrede musste eine entsprechende Vorlage bieten, wenn zugleich mit der Verteidigung des Christentums der Anspruch an eine philosophische Diskussion gewahrt werden sollte. Und so gibt es für jeden der drei oben genannten Abschnitte in der Octaviusrede eine (nachträglich formulierte) negative Vorlage in der Caeciliusrede ${ }^{83}$. Durch die jetzige Anordnung und Gestaltung der Reden wird der Eindruck erweckt, Octavius antworte auf die Fragen und Vorwürfe des Heiden Caecilius. Tatsächlich aber musste sich der heidnische Angriff auf das Christentum den traditionellen Antworten der Apologeten unterordnen. Beide Reden dienen damit gemeinsam der Darstellung der christlichen Wahrheit. Damit macht sich Minucius geschickt die spezifischen Möglichkeiten des literarischen Dialogs zunutze: Er bildet eine Pluralität ab, die Leseridentifikation ermöglicht, stellt diese aber von Anfang an in den Dienst seiner eigenen Argumentation.

Minucius nutzt die Multiperspektivität des literarischen Dialogs aber nicht nur auf der argumentativen, sondern auch auf der narrativen Ebene. Im so genannten Zwischengespräch (Octavius 14f.) meldet sich Minucius in seiner Funktion als Schiedsrichter (arbiter) zu Wort. Es ist die einzige Stelle, an der er dies tut, und das lässt darauf schließen, dass die eigentliche Aufgabe des Schiedsrichters nicht in einem abschließenden inhaltlichen Urteil, sondern in einer Reflexion über das Verhältnis von Christentum und Rhetorik - und damit auch über das Verhältnis von Inhalt und Form eines philosophischen Dialogs besteht ${ }^{84}$. Eine Rüge an Caecilius wegen seines triumphalen Auftretens dient als Überleitung zu einer grundsätzlichen Erörterung über die in philosophischen Disputen übliche Gesprächsmethode (de toto genere disputandi ${ }^{85}$ ). Unter Rückgriff auf eine alte Auseinandersetzung zwischen Philosophie und Rhetorik entwickelt Minucius hier Ansätze zu einer christlichen Disputationstheorie. Die unmittelbare Vorlage ist in diesem Fall ein kurzer Gesprächsgang aus Platons Phaidon ${ }^{86}$. Wie

82 Vgl. Beaujeu, Introduction (wie Anm. 59), XV.

83 Ablehnung des Monotheismus (Min. Fel., Oct. 5,12f.) - Verteidigung des Polytheismus (Oct. 6,1-8,2) - Ethische Verdorbenheit der Christen (Oct. 8,3-12,7).

84 Genau dieselbe Funktion hat der Schiedsrichter in mittelalterlichen Religionsdialogen, etwa in Petrus Abaelards Collationes sive Dialogus inter Philosophum, Indaeum et Christianum oder bei Ramon Llull, Liber gentilis et tribus sapientibus. Diese Parallele ist um so bemerkenswerter, als nichts darauf hindeutet, dass Abaelard oder Llull den Octavius gekannt haben könnten.

85 Min. Fel., Oct. 14,3 (11,19f. K.)

86 Pl., Phd. 89b-91c. Die Parallele wurde zuerst gesehen von J.P. Waltzing, „Minucius Felix et Platon “, in: (ohne Hg.) Mélanges Boissier, Paris 1903, 455-460. Seitdem wurde immer wieder auf vermeintliche Unterschiede zwischen Minucius und Platon aufmerksam gemacht, um die Eigenständigkeit des Minucius hervorzuheben. Eine kritische Überprüfung zeigt jedoch, dass Minucius in der Analyse nicht über Platon hinausgeht: Zum einen geht es auch Minucius um die Gegenüberstellung wahrer und falscher Aussagen und um die Frage, inwiefern die Rhetorik eine Unterscheidung zwischen wahr und falsch erschweren kann. Minucius verlagert die Alternative also nicht, wie Becker behauptete, von den 
Platon sieht auch Minucius die große Gefahr der Rhetorik darin, dass die Redegewandtheit der Gesprächspartner die Wahrheit in verschiedenem Licht erscheinen lassen kann, so dass ungeübte Zuhörer kritiklos von einer Meinung zur anderen hin- und hergerissen werden und schließlich, von ihrer eigenen Leichtgläubigkeit getäuscht, keiner Rede mehr Glauben schenken. Rhetorik, so die These, kann Menschen in die Skepsis treiben. Wie bei Plato, so führt auch bei Minucius diese Beobachtung nicht etwa zu einer grundsätzlichen Ablehnung der Rhetorik oder rhetorisch geschulter Dispute, sondern vielmehr zu einer Ermahnung an die Hörer. Denn nicht in der rhetorischen Kunstfertigkeit der Redner liegt die Gefahr, sondern in der mangelnden rhetorischen Bildung der Zuhörer:

Häufig wird durch die Fähigkeiten der Streitenden und durch die Macht der Redekunst auch die Erscheinungsweise einer ganz offensichtlichen Wahrheit verändert. Es ist allgemein bekannt, dass dies nur infolge der Leichtfertigkeit der Zuhörer geschehen kann, die sich durch die Verführung der Worte von der Aufmerksamkeit für die Dinge selbst ablenken lassen und kritiklos allem zustimmen, was man ihnen sagt, und falsche Aussagen nicht von wahren unterscheiden können. Sie wissen auch nicht, dass auch im Unglaublichen Wahrheit, dass auch auch im Wahrscheinlichen Lüge stecken kann. Und so werden sie denn, sooft sie irgendwelchen Beteuerungen Glauben schenken, sogleich von Klügeren widerlegt. Fortwährend durch ihre eigene Leichtgläubigkeit getäuscht, übertragen sie die Schuld von der urteilenden Person auf eine Klage über die allgemeine Ungewissheit, schließlich, nachdem sie alles verworfen haben, ziehen sie es vor, alles in der Schwebe zu lassen als über schwierige Dinge zu urteilen. Darum müssen wir uns vorsehen, dass wir nicht auch immer wieder dem Widerwillen gegen alle Reden verfallen, so wie einfältige Menschen sich zu Verfluchung und Misstrauen gegen die Menschen hinreißen lassen ${ }^{87}$.

wahren und falschen Logoi auf Rhetorik und schlichte Wahrheit (vgl. Becker, Der „Octavius" [wie Anm. 60], 6-10). Zum anderen führt auch Platon das Problem bereits auf die

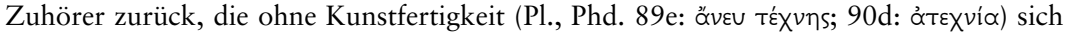
von der Wortgewalt der Redner beeinflussen lassen. Auch dies ist also kein über Platon hinausgehender Gedanke, wie H.A. Gärtner, Die Rolle und Bewertung der skeptischen Methode im Dialog des Minucius Felix, in: M. Wacht (Hg.), Panchaia. Festschrift für Klaus Thraede, JAC.E 22, Münster 1995, (141-147) 147, und P. van der Nat, Zu den Voraussetzungen der christlichen lateinischen Literatur. Die Zeugnisse von Minucius Felix und Laktanz, in: Fuhrmann, Christianisme (wie Anm. 1), 208f. behaupteten. Der einzige wirkliche Unterschied zu Platon besteht darin, dass Minucius als Schiedsrichter diese grundsätzlichen Überlegungen in das Gespräch einbringt, während sie im Phaidon von Sokrates selbst, also einem der Disputanten, vorgetragen werden. Daher ist auch die aus den Überlegungen für den Fortgang des Gesprächs gezogene Konsequenz eine andere: Sokrates kündigt an, eine betont subjektive Antwort auf die Reden von Kebes und Simmias zu geben (Pl., Phd. 91a-c), Minucius dagegen fordert eine Gesprächsmethode, die möglichst große Objektivität garantiert (Min. Fel., Oct. 14,7, [11,33-12,4 K.]).

87 Min. Fel., Oct. 14,3-6 (11,20-30 K.): plerumque pro disserentium viribus et eloquentiae potestate etiam perspicuae veritatis condicio mutetur. id accidere pernotum est auditorum facilitate, qui dum verborum lenocinio a rerum intentionibus avocantur, sine dilectu adsentiuntur dictis omnibus nec a rectis falsa secernunt, nescientes inesse et <in> incredibili verum et in verisimili mendacium. itaque, quod saepius adseverationibus credunt, eo frequentius a peritioribus arguuntur; sic adsidue temeritate decepti culpam iudicis transferunt ad incerti querellam, ut damnatis omnibus malint universa suspendere quam de 
Aus der Einsicht in die Ambivalenz rhetorischer Kunstfertigkeit folgt also die Forderung, sich diese Kunst anzueignen, um angemessen und kritisch mit ihr umgehen zu können. Wie eine solche christliche Indienstnahme der eloquentia praktisch aussehen kann, führt Minucius in der stilistisch ausgefeilten Octaviusrede vor, in der, wie er selbst sagt, , die Wahrheit nicht nur leicht verständlich, sondern auch anziehend dargestellt" ${ }^{\text {"88 }}$ wird.

Man könnte freilich einwenden, dass Octavius selbst ein anderes Ideal christlicher Rede zu vertreten scheint als der Schiedsrichter Minucius ${ }^{89}$, wenn er zu Beginn seiner Rede sagt:

Je einfacher eine Rede ist, desto einleuchtender tritt ihr Sinn hervor, weil er nicht mit dem Prunk der Redegewandtheit und Wohlgefälligkeit aufgeputzt ist, sondern, durch das Richtmaß der Wahrheit so erhalten wird, wie er ist ${ }^{90}$.

Diese Absage an rhetorische Kunstfertigkeit ist aber nicht das Programm des Octavius für sich selbst, sondern eine Verteidigung der von Caecilius kritisierten Tatsache, dass bei den Christen einfache und ungebildete Menschen über das Göttliche sprechen ${ }^{91}$. Dem setzt Octavius entgegen, dass es nicht auf das Ansehen des Disputierenden, sondern auf die Wahrheit der Aussage ankomme (non disputantis auctoritas, sed disputationis ipsius veritas requiratur $)^{92}$.

Minucius schreibt im Zwischengespräch des Octavius die Auseinandersetzung zwischen Platon und den Sophisten fort - und dies, wie schon in der Inszenierung des Caecilius, mit einer antiskeptischen Spitze. An die Stelle der Sophisten bei Platon stellt Minucius die rhetorisch versierten Skeptiker mit ihrer Forderung, sich jeglichen theoretischen Urteils zu enthalten. Eine solche Gleichsetzung von rhetorisch geschulter Sophistik und philosophischer Skepsis war im Umkreis des Minucius alles andere als abwegig. So galt etwa der berühmte und besonders in Rom verehrte Favorinus von Arelate zugleich als Rhetor, Sophist und skeptischer Philosoph ${ }^{93}$.

fallacibus indicare. igitur nobis providendum est, ne odio identidem sermonum omnium laboremus ita, ut in exsecrationem et odium hominum plerique simpliciores efferantur.

88 Min. Fel., Oct. 39,1 (37,8f. K.): ostendisset etiam veritatem non tantummodo facilem sed et favorabilem.

89 So urteilte van der Nat, Voraussetzungen (wie Anm. 86), 211: „Octavius spricht das traditionelle, ablehnende, Minucius selbst hingegen das differenzierte, ,moderne‘ Urteil aus."

90 Min. Fel., Oct. 16,6 (13,13-15 K.): atque etiam, quo inperitior sermo, hoc inlustrior ratio est, quoniam non fucatur pompa facundiae et gratiae, sed, ut est, recti regula sustinetur.

91 Vgl. Min. Fel., Oct. 5,4 (3,22-26 K.): „Darum ist es für alle entrüstend und ärgerlich, dass einige, noch dazu Leute ohne Bildung, ohne Kenntnis der Wissenschaften, die nicht einmal für die niedrigsten Künste zu gebrauchen sind, sich erdreisten, etwas Sicheres über das Weltall und seine Erhabenheit zu behaupten." (Itaque indignandum omnibus indolescendum est audere quosdam, et hoc studiorum rudes, litterarum profanos, expertes artium etiam sordidarum, certum aliquid de summa rerum ac maiestate decernere.) Min. Fel., Oct. 16,6 (13,12f. K.).

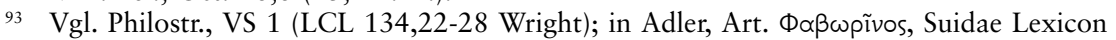

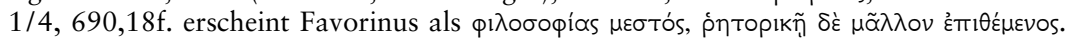


Möglicherweise hatte der Bericht des Aulus Gellius über Favorinus in den um 160 n.Chr. erschienenen Noctes Atticae Minucius jedenfalls in einigen Elementen als Vorlage für seinen Octavius gedient ${ }^{94}$. Auch Miniucius' unmittelbares skeptisches Gegenüber, Sextus Empiricus, wusste sich in seinen skeptischen Betrachtungen einer ausgefeilten Rhetorik zu bedienen, und das selbst dann noch, als er gegen die Rhetoriker polemisierte ${ }^{95}$. Wollte Minucius diesen Persönlichkeiten von christlicher Seite etwas entgegensetzen, so musste er eine Möglichkeit aufzeigen, wie Christentum und Rhetorik miteinander zu vereinbaren waren. Dass sein Plädoyer für eine christliche Sachlichkeit eine kritische Indienstnahme der Rhetorik durch das Christentum nicht ausschließt, sondern sogar erforderlich macht, zeigt nicht nur die explizite Stellungnahme des Minucius im Zwischengespräch, sondern auch die gesamte Gestaltung des Dialogs. Auch in dieser Frage geht Minucius freilich mit der für ihn so charakteristischen „Elastizität“96 mit der Tradition um: Er greift die Kritik der christlichen Apologeten an der heidnischen eloquentia auf, macht aber zugleich deutlich, dass nur eine rhetorische Bildung den notwendigen kritischen Umgang mit ihr ermöglicht. Minucius bedient sich nicht nur rhetorischer Kunstfertigkeit für seine Polemik - wie etwa Tertullian, dessen Apologeticum Minucius als wichtige Quelle diente - sondern bietet im Zwischengespräch auch ein „differenziertes Urteil über die eloquentia [...], das in der christlichen lateinischen Literatur gänzlich neu ist" ${ }^{\text {(97 }}$. Indem er, unter Rückgriff auf Platon, einen unmittelbaren Zusammenhang zwischen Redefeindschaft und Skepsis herstellt, stellt er indirekt auch die Möglichkeit einer Versöhnung

Seine Popularität verdankte er vor allem seinem Schüler und glühenden Verehrer Aulus Gellius, der seinem Lehrer in den Noctes Atticae ein Denkmal gesetzt hat; vgl. M.-L. Lakmann, Favorinus von Arelate. Aulus Gellius über seinen Lehrer, in: B. Czapla/T. Lehmann/S. Liel (Hgg.), Vir bonus dicendi peritus. Festschrift für Alfons Weische zum 65. Geburtstag, Wiesbaden 1997, 233-243; S.M. Beall, Homo fandi dulcissimus. The Role of Favorinus in the Attic Nights of Aulus Gellius, AJP 122/1, 2001, 87-106; A.-M. Ioppolo, The Academic Position of Favorinus of Arelate, Phron. 38, 1993, 182-213.

94 Baehrens vermutete aufgrund der Parallelen (philosophische Diskussion in Ostia mit einem Schiedsrichter, der die argutiae eines Gesprächspartners kritisiert) sogar, Favorinus und sein Kreis in Rom bildeten den unmittelbaren Hintergrund und Anlass für die Abfassung des Octavius (W.A. Baehrens, Literaturhistorische Beiträge III. Zu Minucius Felix, Hermes 50, 1915, [456-463] 460). Auch wenn die These, der Octavius sei in den Jahren 160-163 n.Chr. als unmittelbarer Angriff auf Favorinus und seine Anhänger verfasst worden, vor allem wegen der Priorität Tertullians vor Minucius nicht zu halten ist, sollte man das Kind nicht mit dem Bade ausschütten und Favorinus als Bezugspunkt des Octavius nicht ganz außer Acht lassen, wie es die neuere Forschung zumeist getan hat. Dass Entgegnungen auf literarische Werke erst nach Jahrzehnten geschrieben wurden, war in der Antike keine Seltenheit.

95 Vgl. dazu I. Sluiter, The Rhetoric of Scepticism: Sextus against the Language-Specialists, in: J. Sihvola (Hg.), Ancient Scepticism and the sceptical tradition, Acta Philosophica Fennica 66, Helsinki 2000, (93-123) 104-113.

96 Vgl. Aland, Christentum (wie Anm. 54).

97 Van der Nat, Voraussetzungen (wie Anm. 86), 210. Zum Verhältnis von Rhetorik und Christentum in vorkonstantinischer Zeit vgl. P. Gemeinhardt, Das lateinische Christentum und die antike pagane Bildung, STAC 41, Tübingen 2007, 63-113. 
von Philosophie und Rhetorik durch die Skeptiker seiner Zeit in Frage. Die christliche Lehre, „leicht verständlich und anziehend“ zugleich vorgetragen $^{98}$, erscheint damit auch in dieser Hinsicht als die vera religio. Und wie im Vorübergehen gibt Minucius im Zwischengespräch des Octavius zugleich seinen christlichen Lesern eine Legitimation dafür, dass er seine Apologie in die Form des rhetorisch anspruchsvollen literarischen Dialogs gekleidet hat.

\section{Transformationen - Fazit und Ausblick}

Die Zusammenschau zweier auf den ersten Blick so unterschiedlicher Werke wie Justins Dialog mit dem Juden Tryphon und Minucius Felix' Octavius mag zunächst befremden. Die Verschiedenheit der Werke lässt sich jedoch relativ leicht mit den unterschiedlichen Gesichtskreisen ihrer Verfasser erklären. Man muss dafür gar nicht die für beide Dialoge intensiv diskutierte, aber wohl nicht endgültig zu beantwortende Adressatenfrage bemühen, zumal die Grenze zwischen Juden und Christen zu Justins Zeit ebenso fließend sein konnte wie die zwischen „Heiden“ und „Christen“ im Umfeld des Minucius ${ }^{99}$. Wichtiger als die genaue Bestimmung der intendierten Leser und aus den Werken heraus einfacher zu beantworten ist die Frage, aus welchem Blickwinkel heraus die Autoren, also Justin und Minucius, das Christentum und seine Umwelt betrachten.

Bei Justin ist dieser Blickwinkel beeindruckend weit: Er wählt sich einen jüdischen Gesprächspartner, weil er die rechte Verhältnisbestimmung zum Judentum (sicherlich zu Recht) als vordringliche Aufgabe seiner Zeit ansah, da sich in ihr alle Herausforderungen der Christen bündeln ließen. Durch die Anknüpfung an das jüdische Erbe konnten zugleich Gemeinsamkeiten

98 Min. Fel., Oct. 39,1 (37,8f. K.), vgl. Anm. 88.

99 Zur Adressatenfrage bei Justin vgl. den Forschungsüberblick bei Bobichon, Justin (wie Anm. 34), 129-166. Im Blick auf den Octavius hat C. Schubert m.E. zu Recht von einer „doppelten Lesbarkeit“ für Heiden und Christen gesprochen: C. Schubert, Heiden oder Christen? Das Zielpublikum von Minucius Felix „Octavius“, in: ders./A. von Stockhausen (Hgg.), Ad veram religionem reformare. Frühchristliche Apologetik zwischen Anspruch und Wirklichkeit, ErF 9, Erlangen 2006, 123-142; in der Tendenz ähnlich (wenn auch weniger gut begründet): Noack, Der „Octavius“ (wie Anm. 66). Dass der Octavius für Gnostiker geschrieben ist, wie Gisela Stölting auf der Basis einer Analyse des Prologs und der szenischen Rahmung vermutet, scheint mir unwahrscheinlich (G. Stölting, Probleme der Interpretation des „Octavius“ von Minucius Felix, Diss. phil., Mannheim 2006). So wichtig und innovativ ihre Analyse der Darstellungsebene des Octavius ist, so vernachlässigt bleibt in Stöltings Interpretation die Argumentationsebene. Passagen wie die Verteidigung des Kreuzes (Min. Fel., Oct. 29,2-8 [28,15-36 K.]) oder das Verständnis irdischen Leidens als Prüfung durch Gott (Oct. 36,3-38,4 [34,12-36,22 K.]) können kaum aus der Hand eines Gnostikers stammen. Dass Minucius auch gnostisches Gedankengut eklektisch aufgenommen hat, ist möglich, aber den Octavius als ein „einer Meditation gleichkommendes Selbstgespräch“ (S. 208) eines Gnostikers zu bezeichnen, schießt über das Ziel - den Nachweis des Einflusses gnostischer Motive - weit hinaus und führt zu einer unangemessenen Engführung der Interpretation. 
und Differenzen mit dem Judentum aufgezeigt und damit die Anziehungskraft des Judentums auf Heiden für die christliche Heidenmission ausgenutzt werden ${ }^{100}$. Da die Auseinandersetzung mit dem jüdischen Erbe des Christentums sich aber nicht nur zwischen Juden, Heiden und Christen, sondern auch innerhalb und am Rande der christlichen Gemeinden in der Konfrontation mit gnostischen und markionitischen Kreisen auswirkten ${ }^{101}$, war die Einheit des Christentums gefährdet, wenn man sich vom gemeinsamen Fundament, den heiligen Schriften und ihrem Gottesbild, entfernte.

Minucius Felix hat in erster Linie Angehörige der gebildeten Mittel- und Oberschicht der römischen Gesellschaft vor Augen. Er sah (wohl ebenfalls zu Recht) in der Verbindung von philosophischer Skepsis und traditioneller römischer Religiosität die wichtigste Ursache für den Widerstand gegen das Christentum zu seiner Zeit. Den literarischen Dialog in Anlehnung an Cicero zu einer Verteidigung des als Religion der Ungebildeten und Verrohten verabscheuten Christentums zu gebrauchen, war sicherlich ein „Wagnis“102. Aber dieses Wagnis eröffnete Minucius die Möglichkeit, die Skepsis mit ihren eigenen Methoden zu unterwandern. Indem er Caecilius zuerst auftreten lässt, zwingt Minucius die Skepsis in das Korsett einer zusammenhängenden Rede - der Skeptiker wird seiner methodischen Waffe beraubt und verfängt sich selbst in Widersprüchen.

Justin und Minucius haben den antiken philosophischen Dialog mit den Traditionen christlicher Apologetik verbunden, weil sie ihren - am Christentum zumindest interessierten - Lesern gangbare Wege für die Annahme und Verteidigung ihres Glaubens in den Diskursen ihrer Zeit aufzeigen wollten. Insofern trifft auch auf die frühchristlichen Dialoge zu, dass sie im Blick auf tatsächlich stattfindende Diskussionen geschrieben wurden ${ }^{103}$. Der Begriff "Gebrauchsliteratur" hat also eine gewisse Berechtigung, wenn damit auf die operative Funktion der Dialoge verwiesen werden soll. Durch die Analyse der Inszenierung der Dialoge sollte aber deutlich geworden sein, dass

100 Zur Anziehungskraft des Judentums auf Heiden und zur Missionskonkurrenz zwischen Juden und Christen im 2./3. Jahrhundert vgl. die Studie von L.H. Feldman, Jew and Gentile in the Ancient World. Attitudes and Interactions from Alexander to Justinian, Princeton 1993, besonders 288-415. Bisweilen wurde Justins Dialog als ein Zeugnis der Missionskonkurrenz zwischen Juden und Christen gelesen, so Voss, Dialog (wie Anm. 1), 38; J. Nilson, To whom is Justin's Dialogue adressed?, TS 38, 1977, 538-546; O. Skarsaune, The proof from prophecy. A study in Justin Martyr's Proof-Text Tradition. Text Type, Provenance, Theological Profile, NT.S 56, Leiden 1987.

101 Justin spricht ausdrücklich von diesen Gruppen: Just., dial. 80,2-5 (208,9-210,3 M.) u.ö.

102 Vgl. Aland, Christentum (wie Anm. 54), 22: „Streitgespräche dieser Art waren diesem (scil. dem heidnischen Leser) aus der Literatur bekannt. Es war ein Wagnis, sie auch auf dieses eigentlich von vornherein unmögliche Thema auszudehnen. Wenn aber der andere überhaupt angesprochen werden sollte, dann wohl nur so.“

103 Schubert, Heiden oder Christen? (wie Anm. 99), 140 bezeichnet den Octavius deshalb zu Recht als „Encheiridion für Christen zur Heidenmission“ und weist darauf hin, dass Cyprian und Laktanz den Dialog tatsächlich so rezipiert haben. 
dies keine Alternative zu „echter Literatur“ darstellt ${ }^{104}$. Das Einwirken auf reale Diskurse gehört zur Pragmatik aller - auch der platonischen - Dialoge. Die christliche Transformation des antiken philosophischen Dialogs bei Justin und Minucius Felix bedeutet keine (und erst recht keine unbewusste) „Erstarrung“ oder „völlige Entstellung“105, sondern eine Erweiterung des Genres, die sich kreativen Aneignungsprozessen verdankt. Die Dialoge Platons und Ciceros dienten Justin und Minucius nicht als Ideal, das es zu imitieren, sondern als Ausgangspunkt, den es zu überwinden galt - zugunsten der Schaffung eines spezifisch christlichen Dialogs. Diese für die Interpretation und Beurteilung der Werke entscheidende Erkenntnis ist von der neuzeitlichen Forschung zu wenig beachtet worden. Die christliche Transformation der philosophischen Dialogtradition war sowohl bei Justin als auch bei Minucius ein sehr bewusster Vorgang. Durch die Wahl der Dialogform untermauern sie literarisch den Anspruch des Christentums, die wahre Philosophie zu sein (wobei beide damit ganz im Sinne ihrer Zeitgenossen die wahre Lebensform meinen). In der spezifischen Art der Transformation des antiken Dialogs spiegelt sich literarisch, worin für Justin und Minucius jeweils das „Neue“ und „Wahre“ dieser Philosophie besteht - bei Justin in der einübenden Auslegung der biblischen Schriften, bei Minucius in der argumentativen und methodischen Überwindung der philosophischen Skepsis.

Die Analyse der Inszenierungsstrategien hat den Blick für die literarische Komplexität der beiden ältesten erhaltenen christlichen Kontroversdialoge geschärft. Die Frage nach der operativen Funktion der Texte in den zeitgenössischen Diskursen hat gezeigt, dass der literarischen eine inhaltliche Komplexität entspricht. Die oben skizzierte Methodik dürfte daher auch für die Interpretation späterer Kontroversdialoge aus christlicher Feder - etwa der von der neueren Forschung zunehmend beachteten mittelalterlichen Religionsdialoge Abaelards, Crispins und Ramon Lulls - fruchtbar sein ${ }^{106}$.

\section{ABSTRACT}

Christian apologetic dialogues are often dismissed as functional literature ("Gebrauchsliteratur"). In this paper the author uses the concept of literary staging ("Inszenierung”) to outline a hermeneutics for Christian dialogues that appreciates them as genuine literature. This hermeneutics is applied to the two oldest preserved examples of this genre: the analysis of literary staging shows Justin's Dialogue with the Jew Tryphon to be progress from a platonic elenctical dialogue to an instructional conversation on the

104 So bei Voss, Dialog (wie Anm. 1), 328; der Sache nach auch bei Külzer, Disputationes (wie Anm. 1), 91f.

105 So Hoffmann, Dialog (wie Anm. 1), 162.

106 Für einen äußerst interessanten und von der neueren Forschung gänzlich vernachlässigten Vertreter des Genres, den griechischen Disputationsroman De gestis in Perside (5./6. Jahrhundert) habe ich eine Analyse nach der hier vorgestellten Methodik im Rahmen meiner Dissertationsschrift durchgeführt: K. Heyden, Die „Erzählung des Aphroditian“. Thema und Variationen, STAC 53, Tübingen 2009, 116-170. 
basis of the Holy Scriptures. The Octavius of Minucius Felix transforms the sceptical method of Cicero into a paradigm of Christian eloquentia. Thus, the specific literary staging of the dialogues reflects what the authors considered to be the new and truthful character of the Christian philosophy: for Justin it is the right exegesis of the biblical scriptures, for Minucius the overcoming of philosophical scepticism in argumentation and method. The concordance of literal form and philosophical content proves both dialogues to be genuine literature. 